(Physiologisches Laboratorium in Bonn.)

\title{
Ueber den Einfluss, welchen Menge und Art der Nahrung auf die Grösse des Stoffwechsels und der Leistungsfähigkeit ausüben.
}

Von

\section{E. Pfingger.}

In halt.

Abschnitt I. Darlegung der Veranlassung dieser Untersuchung:

Es handelt sich um Aufklärung des Räthsels über die nutzlose Zerstörung des Eiweiss, welche Bidder und Schmidt scheinbar bewiesen haben. (S. 425.)

Abschnitt II. Ueber den Einfluss der Menge des gefütterten

Eiweiss auf die Höhe des Stoffwechsels - unter Berück-

sichtigung des Körpergewichtes sowie der Menge und Zusammensetzung der Nahrung. (S. 430.)

Abschnitt III. Die Eiweissverdaung bei der Katze. S. 438.

Abschnitt IV. Die Grundgesetze des Stoffwechsels werden bei

Fütterung mit Fleisch, Fett und Stärke durch Athemversuche an dem Kater festgestellt. (S. 443.)

Absehnitt V. Ergänzende Versuche über den Stoffwechsel des Hundes. (S. 478.)

Abschnitt VI. Zusammenfassung der Hauptergebnisse. (S. 481.)

\begin{abstract}
Abschnitt I.
Darlegung der Veranlassung dieser Untersuchung.

In den letzten Jahren sind mehrere gegen mich gerichtete Streitschriften aus dem Laboratorium von Carl von Voit in München hervorgegangen, welche darzuthun scheinen, dass der Stoffwechsel der Katze sich von dem des Hundes bei Fleischnahrung ganz ausserordentlich unterscheidet. Die Münchener Untersuchungen


finden theilweise eine Stütze in den berühmten Bilanzbestimmungen von Bidder und Sehmidt.

Die Katze soll im Stande sein, annähernd doppelt, ja dreimal so viel Fleisch zu verdauen und zu oxydiren, als ihrem Bedürfnisse gemäss wäre und in Folge dessen die Befähigung haben, aus überschüssig in der Nahrung zugeführtem Fleische grosse Fettmassen zu bilden. Alle bisherigen am Hunde ausgeführten Stoffwechseluntersuchungen deuten sicher darauf hin, dass diesem Fleischfresser die ausserordentliche Befähigung der Katze in der Verwerthung des Fleisches vollkommen fehlt.

Ich hielt es desshalb für nothwendig, zu prüfen, ob die Voraussetzung, die von den Arbeitern des Voit'schen Laboratoriums mit Rücksicht auf die Katze gemacht werden, richtig seien, und ob die Grundgesetze des Stoffwechsels bei diesem Thiere von den bis jetzt festgestellten abweichen. Ich hatte in Folge dessen Gelegenheit, die Grundlehren des Stoffwechsels $\mathrm{zu}$ befestigen und weiter auszubauen.

Nach Bidder und Sihmidt ${ }^{1}$ gebraucht ein Kater von 3,2 Kilogramm 140-150 Gramm Fleisch als Erhaltungsfutter.

Wegen der sehr langen Dauer der Fütterungsversuche ist es unmöglich zu bezweifeln, dass der für das Erhaltungsfutter angegebene Fleischwerth richtig sei.

Daraus folgt aber vorerst Nichts über die Grösse des Stoffwechsels der Katze, weil der Kraftinhalt des Fleisches so veränderlich ist. Im Ochsenfleisch, welches von Bidder und Schmidt gefüttert wurde, schwankt nach König's Tabellen ${ }^{2}$ ) der Fettgehalt von $55,1 \%$ mit 10,9 Stickstoffsubstanz bis $0,9 \%$ mit 21,8 Stickstoffsubstanz. Vernachlässigt man, was hier geschehen darf, das Glykogen und setzt man $1 \mathrm{~N}$ rund $=27$ grosse Wärmeeinheiten, so hat man für 100 Gramm sehr fettes Ochsenfleisch:

$$
\begin{aligned}
1,8 \text { Gramm } N & =48,6 \text { grosse Wärmeeinheiten } \\
55,1 \quad \text { Fett } & =523,5 \\
\text { Summa } & =572,1 \text { grosse Wärmeeinheiten. }
\end{aligned}
$$

1) Bidder und Schmidt, Die Verdauungssäfte und der Stoffwechsel S. 333.1852.

2) König, Nahrungs- und Genussmittel. Aufl. 3. 1889. Bd. 1 S. 187. 
Dagegen 100 Gramm magerstes Ochsenfleisch ergeben:

3,5 Gramm N $=81,0$ grosse Wärmeeinheiten

$0,9 \quad$ Fett $=85,5 \%$ Summa $=166,5$ grosse Wärmeeinheiten.

Wenn man also die als Erhaltungsfutter nöthige Fleischmenge bestimmt und diesen Werth zur Ermittelung des Nahrungsbedürfnisses benutzen will, ohne die Zusammensetzung des Fleisches zu kennen, so kann man sich dabei um mehrere Hundert Procent irren.

Wenn ein Versuch länger dauert, alsó wie bei Bidder und Schmidt bis zu 6 Wochen, so werden sich die Verschiedenheiten, welche in der Zusammensetzung des Fleisches vorkommen, mehr oder weniger ausgleichen.

Bidder und Schmidt haben nun angegeben, welche $\mathrm{Zu}$ sammensetzung das von ihnen gefütterte Fleisch besass. Man muss annehmen, dass es sich um die mittlere Zusammensetzung handelt, weil die Zahlen sonst werthlos wären, und weil diese Forscher ${ }^{1}$ ) ausdrücklich sagen (allerdings mit Bezug auf eine andere Versuchsreihe):

„Um den Umfang der Kohlensäure- und Harnstoff bildung bei "ungehinderter möglichst reicher Aufnahme von Albuminaten und "Kohlenwasserstoffen gegenüber dem möglichst niedrigen Maasse „des Stoffumsatzes während längerer Inanitionsdauer festzustellen, "wurde einer gesunden fast erwachsenen Katze von 2,18 Kilogramm "Körpergewicht im Beginn der Versuchsreihe an den 8 ersten „Beobachtungstagen täglich so viel frisches zerschnittenes Ochsen„fleisch dargeboten, als dieselbe fressen mochte, die jedesmal auf„genommene Fleischmenge theils durch Rückwägen, thẹls durch "Darreichen schon gewogener Mengen bestimmt, und von Tage zu „Tage je 5 Procent der wohl durcheinander gemengten Fleisch"stïcke zur Analyse aufgehoben u. s. w."

Offenbar sind dann alle diese zur Analyse gesammelten Portionen getrocknet, gemischt und pulverisirt worden, sodass die Analyse die mittlere Zusammensetzung ergeben musste.

Die Menge des Erhaltungsfutters ist von diesen Forschern durch 2 Versuchsreihen bestimmt. Die erste Reihe dauerte 9 Tage und die zweite Reihe 6 Wochen, während welcher das Gewicht des Thieres constant blieb. In der ersten Reihe war Wassergenuss

1) Bidder und Schmidt a. a. 0. S. 292. 
gestattet, in der zweiten nicht. Beide Reihen führen zu annähernd demselben Ergebniss.

In der ersten Reihe wurde gefunden als Erhaltungsfutter 142,41 Gramm Fleisch, in der zweiten 150,00 Gramm Fleisch.

Die Katze wog 3,25 Kilogramm.

100 Theile des gefütterten Fleisches der ersten Reihe enthielten:

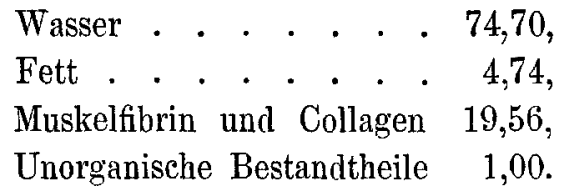

Mit Rücksicht auf den Werth dieser Fleisch-Analyse muss nun leider hervorgehoben werden, dass keine analytischen Belege gegeben werden. "Wir bedauern," ${ }^{1}$ ) sagen Bidder und Schmidt ${ }^{2}$ ) "von "unserem Grundsatz, die sämmtlichen directen Ergebnisse der Ana"lyse mitzutheilen, in dieser und den folgenden Versuchsreihen ab„stehen zu müssen, da das Volumen dieser Abhandlung dadurch einer"seits ungebührlich (um 10-12 Druckbogen) vermehrt, andererseits "aber die Uebersicht der Resultate sehr erschwert würde."

Es wird sich bald zeigen, dass es sehr wünschenswerth wäre, wenn man wüsste, wie viele Analysen gemacht sind, wie sie stimmen, und vor allen Dingen, wer sie ausgeführt hat. Denn in der Vorrede $\mathrm{zu}$ ihrem Buche bedanken sich $\mathrm{Bidder}$ und $\mathrm{Schmidt}$ für die "thätige Mitwirkung" mehrerer ihrer Schüler und nennen Jacubowitsch, Stackmann, Lenz, Schellbach, Zander, Hübbenet u. s. w.

Vor der Hand müssen wir uns an die von Bidder und Schmidt mitgetheilten Zahlen halten.

Ich will nun nach unseren jetzigen Grundsätzen den Kraftinhalt des Erhaltungsfutters, gestützt auf die Bilanz ${ }^{2}$ ) von Bidder und $\operatorname{Schmidt}$, für die erste Reihe berechnen.

Einnahme in 9 Tagen:

40,39 Gramm N $=1080,8$ grosse Wärmeeinheiten, 60,75 "Fett $=577,1 \% "$ Summa $=1657,9$ grosse Wärmeeinheiten.

Das macht für die Katze von 3,2 Kilogramm und 24 Stunden: 184,2 grosse Wärmeeinheiten.

1) Bidder und Schmidt, a. a. O. S. 294.

2) Bidder und Schmidt, a. a. 0. S. 334. 
Darauf bestimmten Bidder und Schmidt den Stoffwechsel derselben Katze bei "grösstmöglicher Nahrungsaufnahme", die in Fleisch bestand. Während in der ersten Reihe die Katze täglich nur 142,41 Gramm Fleisch erhalten hatte, bekam sie jetzt 247,32, also fast doppelt so viel.

Auf Grund der Bilanz von Bidder und Sch midt ${ }^{1}$ ) findet man:

In 24 Stunden der Katze von 3,2 Kilogramm zugeführt und von ibr umgesetzt:

$$
\begin{aligned}
7,79 \text { Gramm } N & =208,46 \text { grosse Wärmeeinheiten, } \\
11,72 \quad \text { Fett } & =111,37 \\
\text { Summa } & =319,83 \text { grosse Wärmeeinheiten. }
\end{aligned}
$$

Also vorausgesetzt eine Katze von 3,2 Kilogramm Gewicht: bei Zufuhr von

142,41 Gramm Fleisch Stoffwechsel $=184,2$ Wärmeeinheiten,

$247,32 \quad " \quad=319,8 \quad "$

Denn laut Bilanz ist bei allen Versuchen nicht bloss der zugeführte Stickstoff, sondern auch der Kohlenstoff in den Ausgaben wieder erschienen.

Diese Versuche bezeugen, dass die Grösse des Stoffwechsels der Zufuhr an Fleisch proportional wächst, ja dass eine gefütterte Fleischmenge, welche das Bedürfniss um annähernd das Doppelte übertrifft, auch vollkommen oxydirt wird, obwohl das Thier in beiden Fällen nahezu dasselbe Gewicht hatte.

M. Cremer ${ }^{2}$ ) fütterte im Laboratorium von Carl von Voit eine Katze von nicht angegebenem Gewicht mit täglich 450 Gramm Fleisch, d. h. mit einer Menge, die das von Bidder und Schmidt ausgemittelte Erhaltungsfutter um das Dreifache übertrifft. Er sagt, dass es ihm gelungen sei, die Stickstoffausscheidungen „bis zur kolossalen Höhe von $5 \mathrm{~N}$ pro Kilo Thier zu steigern". Es soll wohl heissen: 5 Gramm $\mathbf{N}$ in 24 Stunden. Die Katze von Bidder und Schmidt, welche 3,2 Kilogramm wog, würde also im Tage verdaut und zersetzt haben, wenn man $3,2 \% \mathrm{~N}$ im Fleisch annimmt, 500 Gramm Fleisch. Diese Menge übertrifft das Erhaltungsfutter um mehr als das Dreifache.

Ich gehe zur Beschreibung meiner Versuche über.

1) Bidder und Schmidt, a. a. O. S. 337.

2) Cremer, Münch. medic. Wochenschr. Nr. 29 (1897). 


\section{Abschnitt II.}

Ueber den Einfluss der Menge des gefütterten Eiweiss auf die Höhe des Stoffwechsels - unter Berücksichtigung des Körpergewichts sowie der Menge und Zusammensetzung der Nahrung.

Es wurde zunächst der annähernde Bedarf eines gesunden kräftigen Katers ermittelt durch Fütterung mit Pferdefleisch, das mechanisch von Fett möglichst befreit war. Das Gewicht des Thieres wurde Morgens 7 Uhr vor dem Füttern festgestellt mit Hülfe einer Decimalwaage, die 10 Gramm noch gut $\mathrm{zu}$ bestimmen gestattet.

Tabelle I.

\begin{tabular}{|c|c|c|c|c|}
\hline \multirow{2}{*}{$\begin{array}{l}\text { Datum } \\
1898\end{array}$} & \multirow[t]{2}{*}{$\begin{array}{l}\text { Gewicht des } \\
\text { Katers in } \\
\text { Gramm }\end{array}$} & \multirow{2}{*}{$\begin{array}{l}\text { Gewicht des } \\
\text { gefütterten } \\
\text { Fleisches in } \\
\text { Gramm }\end{array}$} & \multicolumn{2}{|c|}{$\begin{array}{c}\text { Temperatur } \\
\text { der Atmosphäre im } \\
\text { Schatten in }{ }^{\circ} \mathrm{C} .\end{array}$} \\
\hline & & & Maximum & Minimum \\
\hline 7. October & 3700 & 200 & 13,9 & 10,7 \\
\hline 8. & 3700 & 200 & 13,9 & 9,7 \\
\hline 9. & 3700 & 200 & - & 一 \\
\hline 10. & 3700 & 200 & 14,6 & 4,2 \\
\hline 11. & 3700 & 200 & 16,0 & 8,8 \\
\hline 12. & 3700 & 200 & 11,9 & 8,7 \\
\hline 13. & 3700 & 200 & 12,4 & 6,8 \\
\hline 14. & 3700 & 500 & 8,2 & 2,5 \\
\hline 15. & 3750 & 500 & 12,2 & 5,8 \\
\hline 16. & 3820 & 500 & - & - \\
\hline 17. & 3920 & 500 & 13,7 & 8,9 \\
\hline
\end{tabular}

Die schnelle und bedeutende Gewichtszunahme des Thieres bei Fütterung mit 500 Gramm zeigte, dass zu viel zugeführt worden war; da der Kater in den 4 Tagen 220 Gramm an Gewicht zugenommen, und 2000 Gramm Fleisch erhalten hatte, so muss er annähernd 1780 Gramm verbraucht haben, oder etwas weniger als 445 Gramm in 24 Stunden. Fin Theil der Gewichtszunahme ist durch nicht verdautes Fleisch bedingt, das sich noch im Magen befindet. Das Futter wurde also verringert. 
Tabelle II.

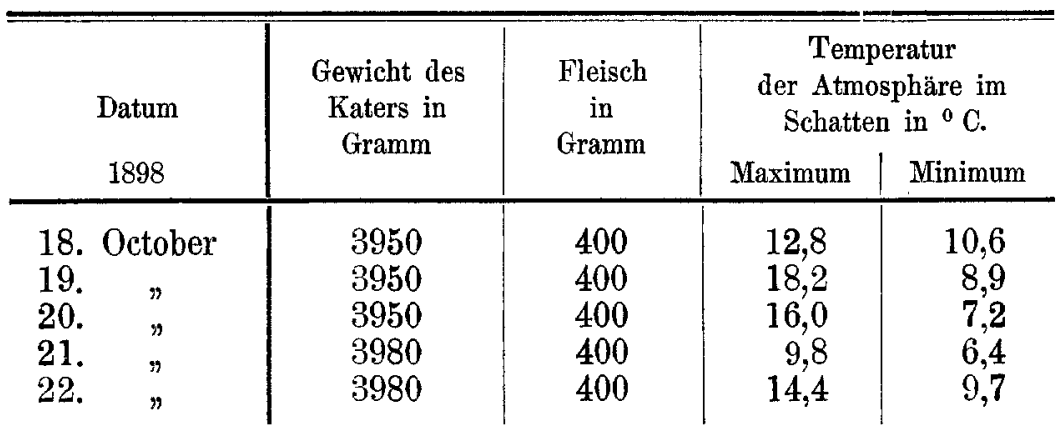

Da 400 Gramm immer noch etwas zu viel schienen, wurde wieder auf 200 Gramm Fleisch zurückgegangen, weil diese bei dem Anfangsgewicht des Thieres das Bedürfniss zu decken schienen.

Tabelle III.

\begin{tabular}{|c|c|c|c|c|}
\hline \multirow{2}{*}{$\begin{array}{l}\text { Datum } \\
1898\end{array}$} & \multirow[t]{2}{*}{$\begin{array}{c}\text { Gewicht des } \\
\text { Katers }\end{array}$} & \multirow[t]{2}{*}{$\begin{array}{l}\text { Fleisch } \\
\text { in } \\
\text { Gramm }\end{array}$} & \multicolumn{2}{|c|}{$\begin{array}{c}\text { Temperatur } \\
\text { der Atmosphäre im } \\
\text { Schatten in }{ }^{\circ} \mathrm{C} .\end{array}$} \\
\hline & & & Maximum & Minimum \\
\hline 23. Octuber & 3970 & & - & - \\
\hline 24. & 3930 & & 14,1 & 11,8 \\
\hline 25. & 3820 & & 14,6 & 7,4 \\
\hline 26. & 3800 & & 13,4 & 10,3 \\
\hline 27. & 3750 & & 15,1 & 12,5 \\
\hline 28. & 3750 & & 15,3 & 3,1 \\
\hline 29. & 3720 & 200 & 15,4 & 7,1 \\
\hline 30. & 3720 & & - & - \\
\hline 31. & 3700 & & 15,0 & 11,5 \\
\hline 1. November & 3700 & & - & 一 \\
\hline 2. & 3700 & & 17,7 & 0,3 \\
\hline 3. & 3700 & & 12,5 & 1,8 \\
\hline 4. & 3700 & & 13,8 & 8,7 \\
\hline 5. & 3700 & & 11,7 & 0,7 \\
\hline
\end{tabular}

Wenn man die Zeit vom 7. bis 14. October mit der vom 31. October bis 5. November vergleicht, ergibt sich eine sehr schöne Uebereinstimmung:

3700 Gramm Katze verdauen und oxydiren 200 Gramm Fleisch in 24 Stunden. 
Betrachtet man diese Fütterungsperiode, so scheint es auf den ersten Blick bewiesen, dass die Katze befähigt sei, wenigstens doppelt so viel Eiweiss zu verdauen und zu zersetzen, als ihrem Bedürfniss entspricht. Diese Schlussfolgerung ist aber nicht gestattet, weil möglicher Weise das als Erhaltungsfutter gereichte Fleisch reicher an Fett und Glykogen war als gewöhnlich.

Ich hielt es desshalb für nöthig, durch einen strengeren Versuch die Grösse des Nahrungsbedürfnisses sicher zu stellen.

Eine grosse Menge frisches Pferdefleisch wurde von Sehnen und Fett mechanisch möglichst befreit, auf der Wurstmaschine in einen feinen Brei verwandelt und dieser, nachdem er gut gemischt worden war, genau auf seinen Gehalt an Fett, Glykogen und Stickstoff untersucht.

Da ein Mann so viele Analysen gleichzeitig auszuführen nicht im Stande ist, wurde ich von meinen beiden sachkundigen Assistenten, Herren Dr. J. Nerking und B. S chöndorff, unterstützt. Dr. Nerking bestimmte das Fett, B. Schöndorff den Stickstoff, und ich das Glykogen.

Stickst offbestimmung.

$$
\begin{aligned}
\text { Analyse I } & =3,198 \% \text { Stickstoff } \\
\text { Analyse II } & =3,223 \% \\
\text { Analyse III } & =3,196 \% " \\
\text { Analyse IV } & =3,201 \% \\
\text { Mittel } & =3,2045 \% \text { Stickstoff. }
\end{aligned}
$$

Fettbestimmung (Verdaungsmethode).

$$
\begin{aligned}
\text { Analyse I } & =1,742 \% \text { Fett } \\
\text { Analyse II } & =1,677 \% \\
\text { Analyse III } & =1,609 \% \\
\text { Analyse IV } & =1,549 \% \\
\text { Mittel } & =1,644 \% \text { Fett. }
\end{aligned}
$$

Bestimmung des Glykogenes nach Külz-Pflüger.

Analyse $\mathrm{I}=2,1902 \%$ asche- und eiweissfreies Glykogen, Analyse II $=2,1900 \% \quad " \quad "$ Mittel $=\overline{2,190 \%}$ asche- und eiweissfreies Glykogen. 
Ueber den Einfluss, welchen Menge und Art der Nahrung etc.

Aus diesen Werthen folgt:

100 Gramm Fleisch

$$
=1,644 \% \text { Fett }=15,6 \text { grosse Wärmeeinheiten }
$$

100 Gramm Fleisch

100 Gramm Fleisch

$$
=2,190^{\circ} / 0 \text { Glykogen }=8,979 \quad " \quad "
$$

$$
\begin{aligned}
=3,205 \% \mathrm{~N} & =85,770 " \\
\text { Summe } & =110,349 \text { grosse Wärmeeinheiten }
\end{aligned}
$$

200 Gramm dieses Fleischbreies enthielten also einen Kraftinhalt, der entsprach in runder Summe:

220,7 grossen Wärmeeinheiten.

Vom Fleischbrei waren je 200 Gramm abgewogen, in Glasbüchsen im Dampfbad sterilisirt und dann hermetisch verschlossen worden.

Der Kater erhielt täglich den Inhalt einer Büchse:

Tabelle IV.

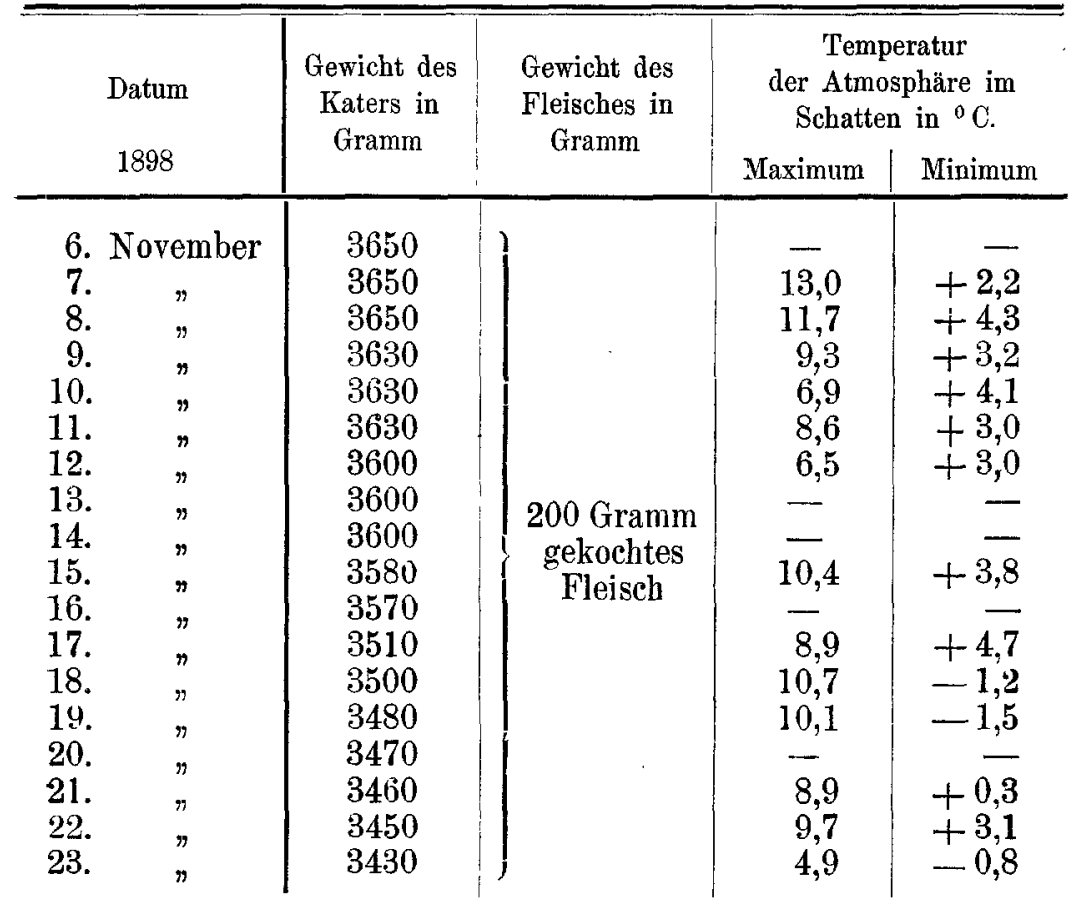

Es konnte hiernach kein Zweifel sein, dass 200 Gramm dieses Fleisches den Bedarf nicht deckten. Desshalb gab ich von jetzt ab täglich eine Zulage von 10 Gramm Schweineschmalz mit folgendem Ergebniss: 
Tabelle V.

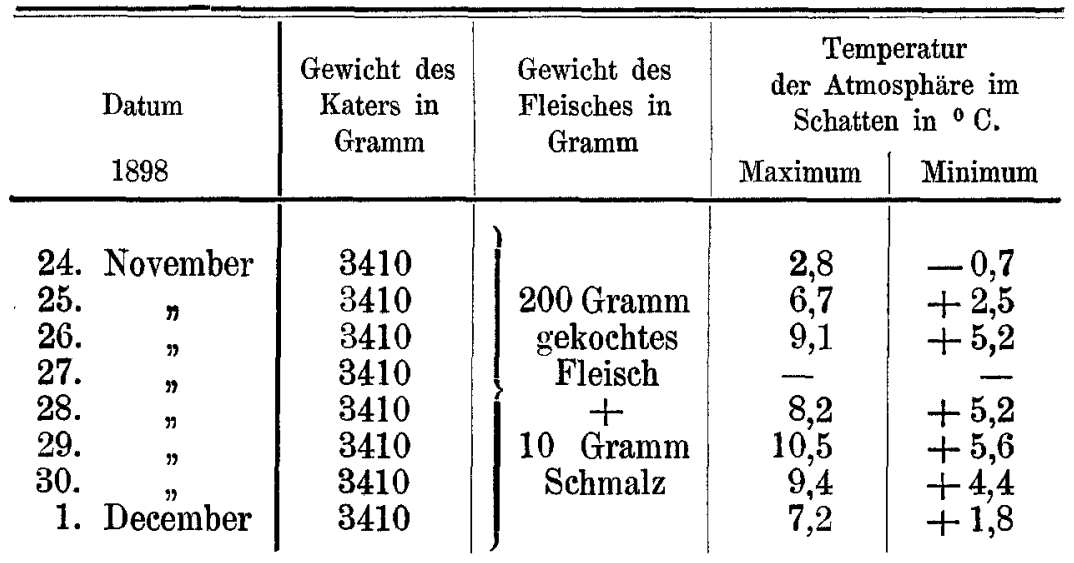

Um das Ergebniss der Tabelle $V$ nochmals auf die Probe zu stellen, setzte ich den Versuch fort, indem ich eine weitere Zulage von 4 Gramm Schmalz gab.

Tabelle VI.

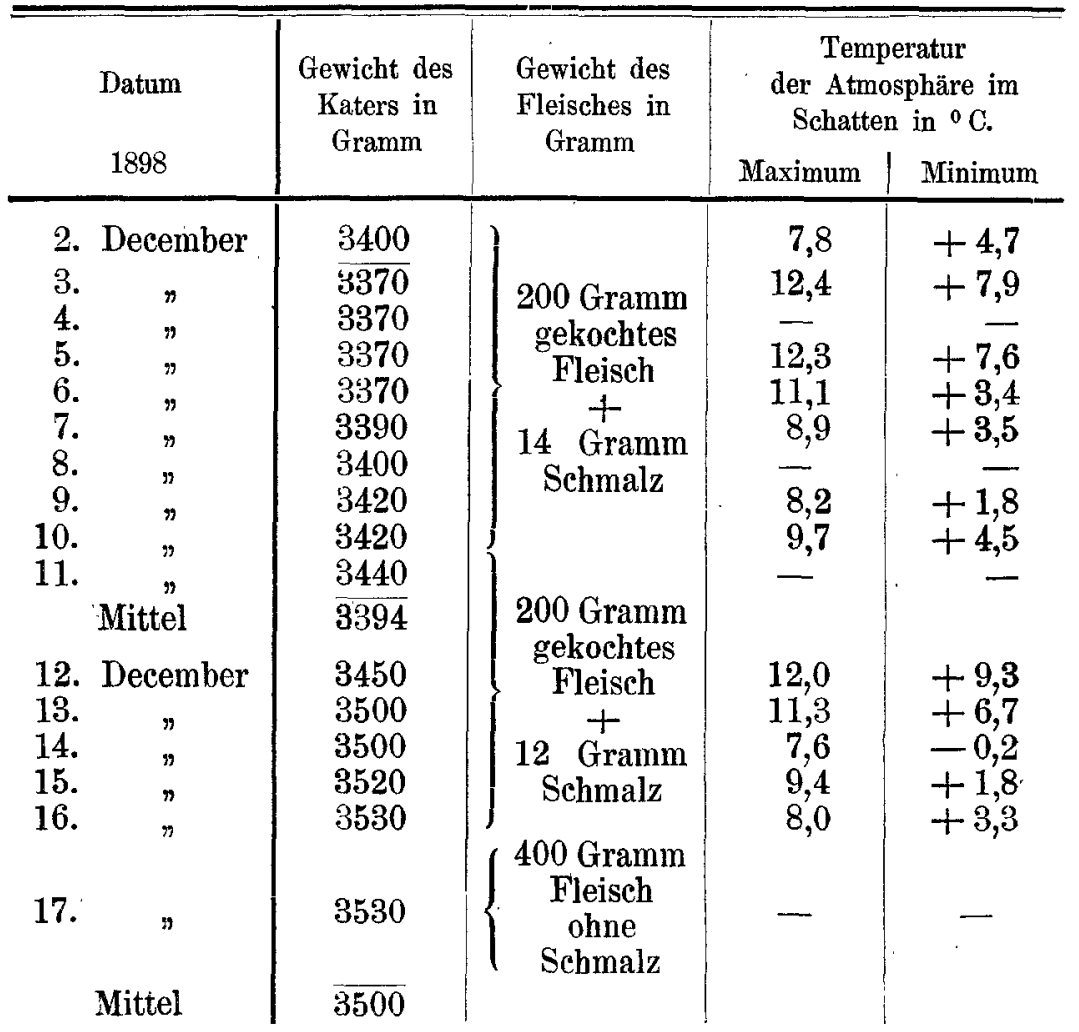


Die Berechnung des Erhaltungsfutters aus dem Körpergewicht des Katers stösst hier auf Schwierigkeiten, weil dasselbe vom 1. December ab grössere Unregelmässigkeiten darbot, die besonders durch die Unregelmässigkeit der Kothentleerung bedingt sind. Denn Wasser erhielt der Kater nie; auch verschmähte er es, wenn es ihm geboten wurde.

Für die Berechnung bitte ich zu beachten, dass das Körpergewicht des Thieres Morgens vor der Fütterung festgestellt wurde. Das an einem bestimmten Tage ermittelte Gewicht des Thieres ist also durch das Futter des vorhergehenden Tages beeinflusst. Die Schmalzzulage von 14 Gramm fand zuerst am 2. December 1898 statt, aber erst das Gewicht am Morgen des 3. December kann durch diese Zulage beeinflusst sein. Weil die Darreichung der Fettzulage am 16. December (incl.) aufhörte, ist das Gewicht am 17. December Morgens noch durch sie beeinflusst: - im Ganzen also 15 Tage.

Das mittlere Gewicht betrug, während die Schmalzzulage 10 Gramm ausmachte, genau 3409 und war für eine ganze Woche vollkommen constant. Die gesteigerte Schmalzzulage war in den 15 Tagen 198 Gramm, also im Mittel 13, 2 Gramm auf 1 Tag.

Das Thier nahm allmälig an Gewicht zu. Es hat sich in Folge der Erhöhung der Schmalzzulage von 10 auf im Mittel 13,2 Gramm erhöht, von im Mittel 3409 auf im Mittel 3438,6 Gramm - in einem Zeitraum von 15 Tagen. Diese Gewichtszunahme kann nicht wohl anders als durch Fett bedingt angesehen werden. Demnach war die tägliche Zulage von im Mittel 13,2 Gramm Sehmalz um 2,0 Gramm zu hoch, so dass als richtige Zulage 11,2 Gramm Schmalz gesetzt werden muss. Es ergibt sich als Erhaltungsfutter:

200 Gramm Fleisch $=220,7$ grosse Wärmeeinheiten

$\begin{aligned} 11.2 & \text { Fett }=106,4 \\ \text { Stoffwechsel }=\text { Summe } & =327,1 \text { grosse Wärmeeinheiten. }\end{aligned}$

Ein Kater von 3439 Gramm mittlerem Gewicht braucht also in der Nahrung 327,1 grosse Wärmeeinheiten.

Ich werde im Verlaufe dieser Abhandlung auch noch durch Athmungsversuche den Beweis beibringen, dass die hier für die Grösse des Stoffwechsels bei Erhaltungsfutter mitgetheilte Zahl richtig ist.

Um nun zu sehen, ob der Kater in der That eine Eiweissmenge, die den Bedarf um ein Mehrfaches übersteigt, zu verdauen und zu oxydiren vermöge, fütterte ich das Thier mit den grösstmöglichen. 
Fleischmassen. Um dies zu erzielen, muss man das Fleisch ganz frisch und roh reichen und in wiederholten Portionen, so zwar, dass immer in der Nacht das Futter zur Verfügung des Thieres bleibt. Morgens wird vor dem Wägen der Katze das nicht gefressene Fleisch zurückgewogen. Dieses Verfahren, welches die genaue Bestimmung des Kraftinhaltes des Fleisches ausschliesst, ist doch zulässig, weil nach bekannten Erfahrungen ein Thier fast nur von Eiweiss lebt, wenn sicher dieser Stoff in einer Menge zugeführt wird, welche das Nahrungsbedürfniss deckt oder übertrifft. Fett und Kohlehydrate des gefütterten Fleisches betheiligen sich in diesem Falle nicht oder kaurn an dem Stoffwechsel und tragen als Mast nur zur Erhöhung des Gewichtes des Thieres bei.

Das Ergebniss der Ueberfütterung mit Fleisch ergibt sich aus folgender Tabelle:

Tabelle VII.

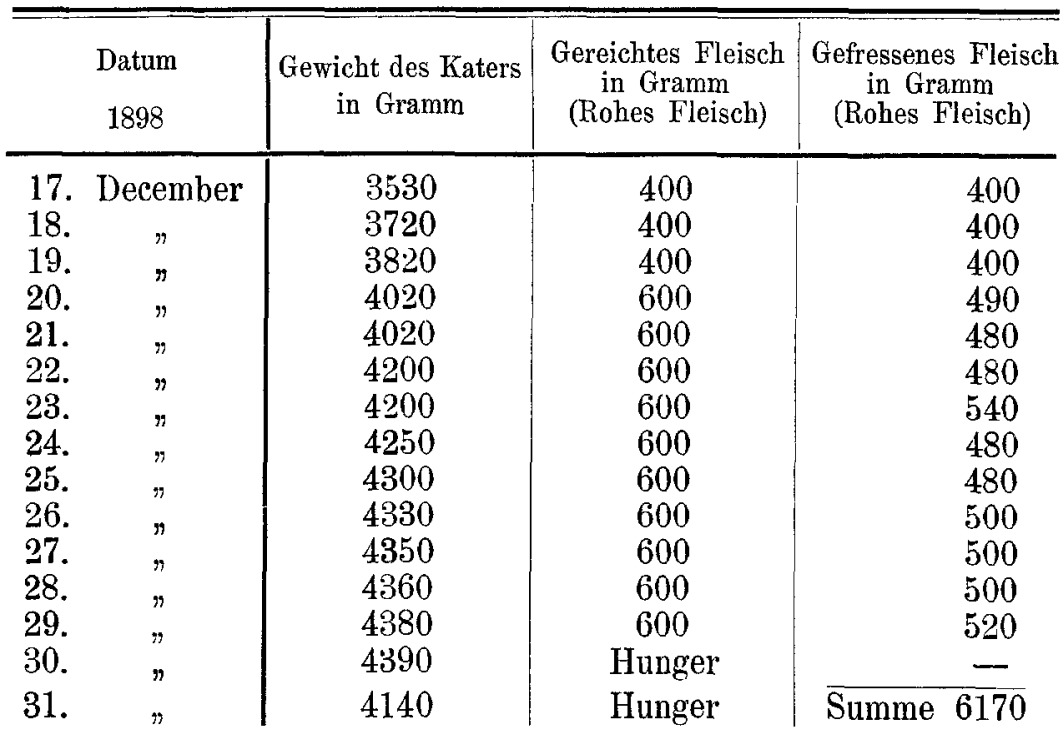

Betrachten wir das Ergebniss der Fütterung mit überreichlichen Fleischmengen, so finden wir, dass das Gewicht des Katers von 3530 auf 4390 , d. h. um 860 Gramm $(24,96 \%$ ) in 12 Tagen zugenommen hat.

Von besonderer Wichtigkeit erscheint aber die Thatsache, dass die Gewichtszunahme des Thieres von Tag zu Tag kleiner wird, um in den letzten Tagen fast mit den Beobachtungsfehlern von einerlei Ordnung zu sein. Die jetzt noch vorhandene Gewichtszunahme ist 
die nothwendige Folge der Ablagerung des im gefütterten Fleisch enthaltenen Glykogenes und Fettes.

Wenn man voraussetzt, dass das bei den letzten Versuchen von uns benutzte Fleisch dieselbe Zusammensetzung wie das von uns analysirte besass, so würde der Kater in den letzten 6 Tagen (vom 24. bis 30. December) im Fleische täglich 8,17 Gramm Fett $+10,9$ Gramm Glykogen aufgenommen haben, also 19,07 Gramm, welche sich zur Mästung ablagern, nachdem ein Theil des Glykogenes in Fett übergegangen ist. -- Nun beträgt die wirkliche mittlere Zunahme des Katers in 24 Stunden 23,3 Gramm, stimmt also hinreichend mit der berechneten Menge überein.

Also auch bei der Katze zeigt sich das beim Hunde bereits festgestellte Gesetz, dals bei beliebig grosser Vermehrung der Eiweisszufuhr der Eiweissstoffwechsel allmälig wächst, bis ebenso viel oxydirt als zugeführt, richtiger wohl, als verdaut wird. Bei diesen Versuchen mit der Katze sind wir sicher bis zur äussersten Grenze des Möglichen gegangen. Ich gebe zu, dass eine strengere Beweisführung für die vollständige Oxydation des verdauten und resorbirten Eiweisses die Aufstellung einer Bilanz des Kohlenstoffs und Stickstoffs verlangt. Es ist aber wenig wahrscheinlich, dass die Ausführung dieser Stoffwechselversuche zu einem anderen Ergebniss führen würde als dem, zu dem auch Voit beim Hunde gelangt ist.

Nimmt man in der für die täglich dem Stoffwechsel verfallene Fleischmenge von 497 Gramm (Mittel der letzten 6 Tage) einen Gehalt von $3,2 \% \mathrm{~N}$, so hat man 15,9 Gramm Stickstoff $=$ 425,5 grosse Wärmeeinheiten.

Solange das Thier 3439 Gramm wog, hatte es einen Bedarf von 327,1 grossen Wärmeeinheiten.

Die Untersuchung hat uns durch Ueberfütterung mit Fleisch $\mathrm{zu}$ einem wichtigen Ergebniss geführt:

I. Der Stoffwechsel ist gestiegen absolut von 327,1 auf 425,5 grosse Wärmeeinheiten.

Beide Werthe verhalten sich wie $100: 130$.

II. Das Körpergewicht ist gestiegen absolut von 3439 (Mittel) auf 4352 (Mittel).

Beide Werthe verhalten sich wie $100: 126,5$. 
Bei Ueberfütterung mit Fleisch wächst also der Stoffwechsel genau proportional der Zunahme des Körpergewichtes.

Das ist nur denkbar, wenn der Stoff, welcher die Gewichtszunahme bedingt, sehr nahe dieselbe mittlere Zusammensetzung hat wie der lebendige Körper selbst. Mit einem Worte: fast alle Organe sind gewachsen.

Weil das Gehirn und die Knochen eine, wenn auch vielleicht nicht absolute Ausnahme von dieser Regel bilden, sollte man meinen, dass bei der Fleischmästung der Stoffwechsel in etwas rascherem Verhältniss als das Körpergewicht wachsen müsse. Dies wird offenbar aber deshalb nicht beobachtet, weil das Gewicht der Substanz, welche sich als Mast im Thierkörper abgelagert hat, auch einen Procentsatz die Höhe des Stoffwechsels nicht bestimmender Materie einschliesst, nämlich Fett und Glykogen, so dass eine Compensation zu Stande kommt.

Ich habe schon früher ${ }^{1}$ ) beim Hunde das Gesetz bewiesen, dass die Höhe des Stoffwechsels dem Gehalt des Thieres an Zellsubstanz proportional ist. Ein Unterschied zwischen Katze und Hund ist also in dieser wichtigen Beziehung nicht vorhanden.

Die Thatsache, dass bei Fleischmästung der Stoffwechsel proportional dem Körpergewichte wächst, ist ganz unvereinbar mit dem durch Bidder und Schmidt scheinbar bewiesenen Gesetz, dass der Stoffwechsel der Katze proportional der Eiweisszufuhr wachsen könne, ohne dass sich das Körpergewicht ändert. Das beweist schon, dass die von Bidder und Schmidt aufgestellte Lehre falseh ist. Wir werden hierfür aber noch weitere Begrundungen beibringen.

Die mitgetheilten Thatsachen machen es möglich, ein Urtheil sich darüber zu bilden, um wie viel die Katze mehr Eiweiss zu verdauen vermöge, als jhrem Bedürfniss gemäss wäre. Es erscheint mir zweckmässig, hierüber erst eingehender zu berichten, nachdem die Athem- und Verdaungsversuche mitgetheilt worden sind.

\section{Abschnitt III.}

Die Eiweissverdaung bei der Katze.

Versuch I.

Eine graue erwachsene Katze, welche seit mehreren Tagen keine Nahrung mehr erhalten hatte, frisst am 7. März 9 Uhr 30 Min.

1) E. Pflüger, Dieses Archiv Bd. 52 S. 1. 
Morgens 200 Gramm rohes Pferdefleisch. - Sie wird um 2 Uhr 45 Min. getödtet. Nach der Eröffnung der Bauchböhle und dann des Magens und Darmes zeigt sich noch sehr viel Fleisch im Magen, während im Dünndarm keine Fleischtheilchen zu sehen sind. Im unteren Theile des Dünndarms findet sich wenig braunschwärzliche Schmiere.

Der aus dem Magen entnommene scheinbar unveränderte Fleischbrei wiegt 163 Gramm. Er enthält $27 \%$ feste Bestandtheile. Es sind also in 5 Stunden 15 Minuten verdaut worden 37 Gramm oder 7,05 in der Stunde.

\section{Versuch II.}

Eine erwachsene Katze, die in den letzten Tagen täglich 50 Gramm rohes Pferdefleisch erhalten hatte, bekam $6^{1 / 4}$ Uhr Morgens 200 Gramm desselben Fleisches und wurde um 4 Uhr geschlachtet; also hatte die Verdauung $9^{3 / 4}$ Stunden gedauert.

Bei der Eröffnung des Magens finden sich darin noch 97,5 Gramm stark stinkendes Fleisch. Das gefütterte Fleisch war ganz frisch gewesen. Der Mageninhalt reagirte sauer. Der Dünndarm ist leer und enthält nur einige braune Schmieren und im unteren Theil ein paar kleine Fleischbröckchen. Der Dickdarm ist mit breiiger brauner Schmiere gefüllt. In 9,75 Stunden hat die Katze also verdaut nur 102,5 Gramm Fleisch, als 010,5 Gramm in einer Stunde.

Der in Versuch I erhaltene niedere Werth könnte bedingt sein entweder dadurch, dass in den ersten Stunden der Verdaung die Einwirkung des Magensaftes noch schwach ist und erst allmälig wächst, oder dadurch, dass ein Thier, das länger gehungert hat, eine Schwächung seiner verdauenden Kraft erleidet.

\section{Versuch III.}

Eine erwachsene Katze frass am 15. April 1899 von 6 Uhr Morgens bis 11 Uhr 370 Gramm rohes Pferdefleisch, nachdem ihr vorher 2 Tage alle Nahrung entzogen worden war. Sie hatte bereits um 7 Uhr über 300 Gramm gefressen, war gesättigt und nahm die Reste bis gegen 11 Uhr ganz auf. Das Thier wurde getödtet $11 \mathrm{Uhr}$ 16. April. 
Der Magen ist ganz leer, ebenso der Dünndarm; am Ende des Dünndarms finden sich Haare, Bandwürmer und ein wenig braune Schmiere.

Die Verdauung hat 29 Stunden gedauert. Es ergibt sich demnach, dass in der Stunde 12,8 Gramm Fleisch verdaut wurden, ein Werth, der sicher zu klein ist.

Diese 3 Versuche können also nicht verwerthet werden zur Bestimmung, wie viel Fleisch eine erwachsene Katze in 24 Stunden verdauen kann.

\section{Versuch IV.}

Ein nicht ganz erwachsener Kater von 1500 Gramm Gewicht wird mit Fleisch gefüttert und erhält, so viel er fressen konnte. Der Kater frass 402 Gramm von $6 \mathrm{Uhr}$ Morgens 18. April an bis $9 \mathrm{Uhr}$ 15 Min. Morgens 19. April, wo er getödtet wurde. Im Magen fanden sich noch 94,3 Gramm unverdautes Fleisch. Die Beschaffenheit des Dünndarms war wie früher angegeben.

Das Thier hatte also verdaut 307,7 Gramm Fleisch in 27,25 Stunden, oder 11,3 Gramm in 1 Stunde, also

271,2 Gramm Fleisch in 24 Stunden oder

181 Gramm Fleisch auf 1 Kilo Thier für 24 Stunden.

\section{Versuch V.}

Eine ausgewachsene nüchterne weibliche Katze von 3250 Gramm Gewicht mit Milch in den stark geschwollenen Brustdrüsen erhielt am 25. April 1899 von 6 Uhr 45 Min. Morgens an so viel Fleiseh, als sie fressen konnte bis zum 27. April 10 Uhr 30 Min. Morgens, wo sie getödtet wurde. Gefressen hat die Katze 940 Gramm Fleisch. Im Magen fanden sich noch unverdaut 147 Gramm stinkendes Fleisch! Im Dünndarm dickliche helle Schmiere, die Schleimhaut in dünner Schicht überziehend, bei mikroskopischer Prüfung aus vielen Zellen bestehend. Die Schmiere ist reichlicher im unteren Theil des Dünndarms, braungefärbt und dicklicher. Im Dickdarm schwarze salbenartige Schmiere. Verdaut hat also das Thier in 51,75 Stunden 793 Gramm Fleisch oder

15,2 Gramm in 1 Stunde, also 364,8 Gramm in 24 Stunden und 112 Gramm auf 1 Kilo Thier. 


\section{Versuch VI.}

Ein nicht ausgewachsener Kater von 1800 Gramm Gewicht erhielt eine ganze Woche so viel Fleisch, als er fressen wollte, $\mathbf{d} . \mathbf{h}$. 500 Gramm täglich. Jeden Morgen wurde zurückgewogen, was er nicht bewältigt hatte. Er verzehrte von 6 Uhr Morgens an

\begin{tabular}{|c|c|c|c|c|c|}
\hline am 21. & April & 330 & Gramm & rohes & Pferdefleisch \\
\hline$\because 22$. & $"$ & 340 & $"$ & $n$ & $"$ \\
\hline$\Rightarrow 23$. & $\eta$ & 320 & $"$ & $n$ & $n$ \\
\hline$\Rightarrow 24$. & $"$ & 360 & $n$ & $"$ & $"$ \\
\hline$\Rightarrow 25$. & $n$ & 340 & $n$ & $n$ & $"$ \\
\hline , 26. & $n$ & 360 & $"$ & $"$ & $n$ \\
\hline, 27. & $"$ & 370 & $"$ & $"$ & $"$ \\
\hline$\Rightarrow 28$. & $n$ & 380 & $"$ & $\eta$ & $"$ \\
\hline$" 29$. & $"$ & $\frac{130}{2930}$ & $\begin{array}{l}\text { Gramm } \\
\text { Gramm }\end{array}$ & $\begin{array}{l}\text { bis } 2 \\
\text { Fleisc }\end{array}$ & $\begin{array}{l}\text { Uhr } 30 \text { Min. } \\
\text { h gefressen, }\end{array}$ \\
\hline
\end{tabular}

in 8 Tagen, 8,5 Stunden $=200,5$ Stunden.

Bei der Eröffnung des Magens fanden sich

103,3 Gramm stark stinkendes Fleisch.

Das Thier hat also in 200,5 Stunden verdaut 2826,7 Gramm rohes Fleisch,

$$
\text { oder 14,1 Gramm in } 1 \text { Stunde und }
$$$$
338,4 \text { Gramm in } 24 \text { Stunden. }
$$

Der Kater wog bei Beginn des Versuches

$$
\begin{aligned}
& \text { am 21. April } 1800 \text { Gramm, } \\
& \text { am 25. April } 2050 \\
& \text { am 29. April } 2450 \quad "
\end{aligned}
$$

Das Thier hat also an Gewicht zugenommen um 650 Gramm, folglich :

1 Kilo dieses Thieres verdante in 24 Stunden 159,2 Gramm rohes Fleisch.

$\operatorname{Denn}\left(1800+\frac{650}{2}\right): 338,4=1000: 159,2$.

Stellt man die drei letzten Versuche, welche in Betracht kommen dürfen, zusammen, so hat man:

Versuch 4: 1500 Gramm (absol. Gewicht des

Thieres). 1 Kilo verdaut in 24 Stunden 181 Gramm Fleisch, E. Pflüger, Archiv für Physiologie. Bd. 77. 
Versuch 5: 3250 Gramm (absol. Gewicht des

Thieres). 1 Kilo verdaut in 24 Stunden 112 Gramm Fleisch, Versuch 6: 1800 Gramm (absol. Gewicht des

Thieres). 1 Kilo verdaut in 24 Stunden 139 Gramm Fleisch.

Man sieht, dass das leichteste Thier - auf die Einheit des Körpergewichts bezogen am meisten, das schwerste Thier am wenigsten verdaut hat. - Setzt man den $\mathrm{N}$-gehalt des Fleisches $=3,2 \%$, so würde die leichteste Katze in 24 Stunden pro Kilo dem Stoffwechsel 5,79 Gramm $\mathrm{N}$ zugeführt haben. Wenn $\mathrm{Cr}$ emer behauptet, eine Ausscheidung von 5 Gramm $\mathrm{N}$ pro Kilo Katze beobachtet zu baben, so ist dies hiernach wohl möglich.

Wie man sieht, scheint die Kraft, mit welcher die Katze Eiweiss verdaut, bei den leichteren (jungen) Thieren viel bedeutender, als sie bei den erwachsenen gefunden wird. Auch meine übrigen zum Theil noch mitzutheilenden Versuche, sowie die von Bidder und $\mathrm{Schmidt}$ bezeugen das gleiche Verhalten. Die schwerere erwachsene Katze verdaut zwar absolut mehr als die jüngere, aber auf die Einheit des Körpergewichts bezogen, bedeutend weniger. Das hat auch einen guten Sinn, weil das jüngere Thier einen lebhafteren Stoffwechsel hat und zum Wachsthum Fleisch ansetzen muss.

Die Zahl der drei verwerthbaren Versuche ist zu klein, um daraus bestimmte Werthe abzuleiten für die Fähigkeit der Katze, das Nahrungsbedürfniss überschreitende Fleischmengen zu verdauen, besonders weil über die Abhängigkeit der Grösse des Nahrungsbedürfnisses vom Alter keine ausreichenden Untersuchungen vorliegen. Dass ich keine grössere Zahl von Versuchen angestellt habe, liegt lediglich daran, dass es hier in Bonn so schwierig ist, Katzen zu erhalten.

Gleichwohl haben die sechs Versuche einige Thatsachen festgestellt, welche für diese Arbeit in Betracht kommen, nämlich:

1. Das Fleisch wird nur im Magen der Katze, nicht im Darme aufgelöst. Im Dünndarm findet man fast niemals ein Fleischklümpchen. Es mag dahingestellt bleiben, ob im Magen gebildete Fleischlösung nach dem Dünndarm gelangt und dort schnell verändert und resorbirt wird. $\mathrm{Zu}$ sehen ist Nichts davon.

2. Die Verdaunng des Fleisches vollzieht sich im Magen der Katze auffallend langsam. In Versuch 1 hatte die Katze so viel 
Fleisch gefressen, wie sie für 24 Stunden ungefähr brauchte, nämlich 200 Gramm. Nach $5^{1 / 4}$ Stunden waren erst 37 Gramm verdaut, d. h. noch nicht $1 / 6$ der Gesammtmenge. - In Versuch 2 hatte eine erwachsene Katze 200 Gramm Fleisch gefressen. Nach 10 Stunden fand sich noch fast die Hälfte des Fleisches unverdaut im Magen vor. Auch die anderen Versuche bezeugen, dass die Magenverdauung für keineswegs in überschüssiger Menge gefüttertes Fleisch weit über 12 Stunden in Anspruch nimmt.

3. Durch länger dauernde Ueberfütterung mit Fleisch scheint die Verdauungskraft zu wachsen. In einem Versuche, den ich noch genauer beschreiben muss, hatte sich mein Kater in's Stoffwechselgleichgewicht gesetzt mit einer täglichen Nahrung von ungefähr 500 Gramm Fleisch. Er verdaute also 21 Gramm Fleisch in der Stunde; es ist der höchste Werth (absolut genommen), den ich beobachtet habe. Das Thier wog aber auch zuletzt 4390 Gramm, sodass die verdauende Kraft gering ist, wenn man sie auf die Einheit des Körpergewichts bezieht.

4. Da überschüssige Fleischmengen so lange im Magen verweilen müssen, ist es nicht auffallend, dass bei länger dauernder Ueberfütterung der Katze mit frischem Fleisch der Mageninhalt gewöhnlich stark stinkt: zum Beweise von Gährung und Fäulniss.

\section{Abschnitt IV.}

Die Grundgesetze des Stoffwechsels werden an dem Kater durch Athemversuche festgestellt.

Da ich für das Bonner physiologische Institut einen etwas grösseren Athemapparat nach Regnault'scher Einrichtung noch nicht habe beschaffen können, bin ich auf Nothbehelfe angewiesen.

Ich beschloss, den Sauerstoffverbrauch des Katers in der Stunde zu messen, da der erhaltene Werth sehr annähernd die Höhe des Stoffwechsels zu beurtheilen gestattet.

Ich construirte also einen viereckigen Blechkasten von 50 Liter Inhalt, dessen Decke einen cylindrisehen Schornstein mit doppelter Wand trug. Durch die weite Oeffnung des Schornsteins konnte das Thier eingelassen werden. Weil sich Wasser in dem Raum der doppelten Schornsteinwand befand, liess sich eine passende, ebenfalls 
cylindrische Krystallisirschale in den mit Wasser gefüllten Graben des Schornsteins stülpen, während eine kleine Röhre an einer anderen Stelle der Decke des Athemkastens der Luft den Austritt gestattete. Nach Verschluss dieser Röhre ist der Athemraum hermetisch abgeschlossen. Wie bei Regnault trägt der Kasten ein Thermometer, ein Zuleitungsrohr zum Sauerstoffgasometer, zwei Zuleitungsröhren für die Aspiratoren, in denen sich Kalilauge befindet. Die Auf- und Abbewegung dieser mit Kalilösung gefüllten Flaschen musste ein Mensch vollziehen. Die eine Flasche stand fest, die andre wurde bewegt.

Ebe das Thier in den Kasten kommt, wird das Thermometer abgelesen; nach Abschluss des 1 Stunde dauernden Versuches nimmt man den Kater aus dem Kasten und schliesst diesen wieder, als ob das Thier darin wäre; man wartet $1 / 4$ Stunde, wäbrend welcher durch Abkühlung die Luft im Athemraum sich zusammenzieht, sodass neuer Sauerstoff aus dem Gasometer nachdringt. Ist die Temperatur beinahe zum Anfangswerth zurückgegangen, beginnt man aufs Neue, mit Hülfe der Aspirationsflasche den Athemraum von der noch in ihm befindlichen Kohlensäure zu reinigen, und fährt fort, bis keine Contraction der Luft des Athemraumes mehr beobachtet werden kann. Diese durch die Absorption der Kohlensäure bedingte Contraction war immer sehr gering. Man liest den Verbrauch von Sauerstoff $a b$, wenn der Athemraum dieselbe Temperatur anfweist, die bei Beginn des Versuches festgestellt worden war.

In blinden Versuchen ist der Apparat auf seine Dichtheit geprüft worden.

Herr Dr. Max Bleibtreu hat mir bei allen Athemversuchen durch seinen Beistand die Ausführung dieser Arbeit ermöglicht, wesshalb ich ihm den herzlichsten Dank ausspreche.

Ich werde nun in einer Tabelle die wesentlichen Thatsachen zusammenstellen. machen.

Zum Verständniss der Tabelle sind einige Erläuterungen zu

Bei den Versuchen am 16. und 17. December, welche sich auf den Stoffwechsel bei Erhaltungsfutter beziehen, musste ich beachten, dass derselbe innerhalb 24 Stunden auf und ab schwankt. Es ist desshalb ein Versuch am 16. December (3 Stunden), ein anderer 
(am 17. December) $22^{1 / 2}$ Stunden nach Aufnahme der Nabrung ausgeführt.

Bei den Versuchen am 22. December handelt es sich um den durch Ueberfütterung mit Fleisch gesteigerten Stoffwechsel. Weil das Thier fast fortwährend frisst, hat es einen immer gefüllten Magen und befindet sich in fortwährender Verdauung. Hier hat die Angabe, wie viel Zeit seit Aufnahme der Nahrung verflossen sei, keinen Sinn. -

Bei dem Versuche vom 25. Januar 1899 handelt es sich um die Fütterung von Stärkebrei, dem Schmalz zugesetzt ist. Solchen Brei frisst der Kater nur, wenn er dureh den stärksten Hunger gezwungen ist. Er leckt aber immer nur wenig auf und braucht Stunden, bis er ganz zu fressen aufhört. Das gilt auch für geschmelzten Reisbrei, obwohl ihm immer viel Fleischbrühe zugefügt war. Wenn sich die Bemerkung in der Tabelle findet, dass der Versuch $1 \frac{1}{2}$ Stunde nach der Fütterung beginnt, so heisst dies, dass der Kater seit 1/2 Stunden an dem Brei leckt.

In dem 5. Stab der Tabelle finden sich Zahlen, welche den Kraftinhalt des Fleisches dureh Schätzung bestimmen. --

Eine grosse Zahl "von Versuchen ist, wie der Leser gesehen hat, mit Fleisch ausgeführt, dessen Zusammensetzung durch Analyse genau bestimmt worden war, sodass sich der Kraftinhalt sicher angeben liess.

Bei anderen Versuchen, vorausgesetzt, dass der Zweck der Arbeit dies erlaubte, wurde das zu fütternde Pferdefleisch gerade so hergestellt, wie das analysirte, die Zusammensetzung aber nicht unmittelbar bestimmt, sondern nach dem bereits analysirten berechnet. 
Tabelle VIII.

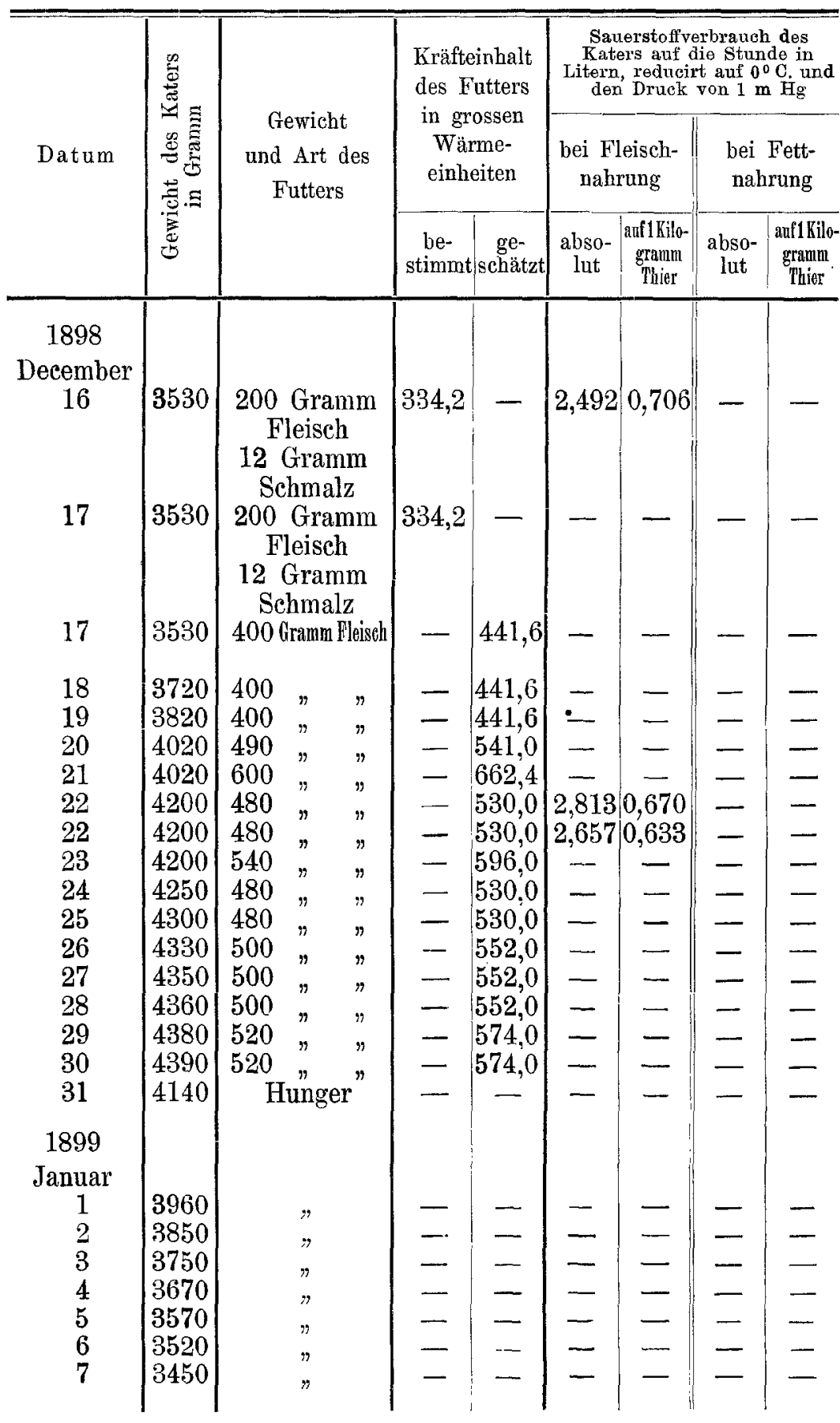




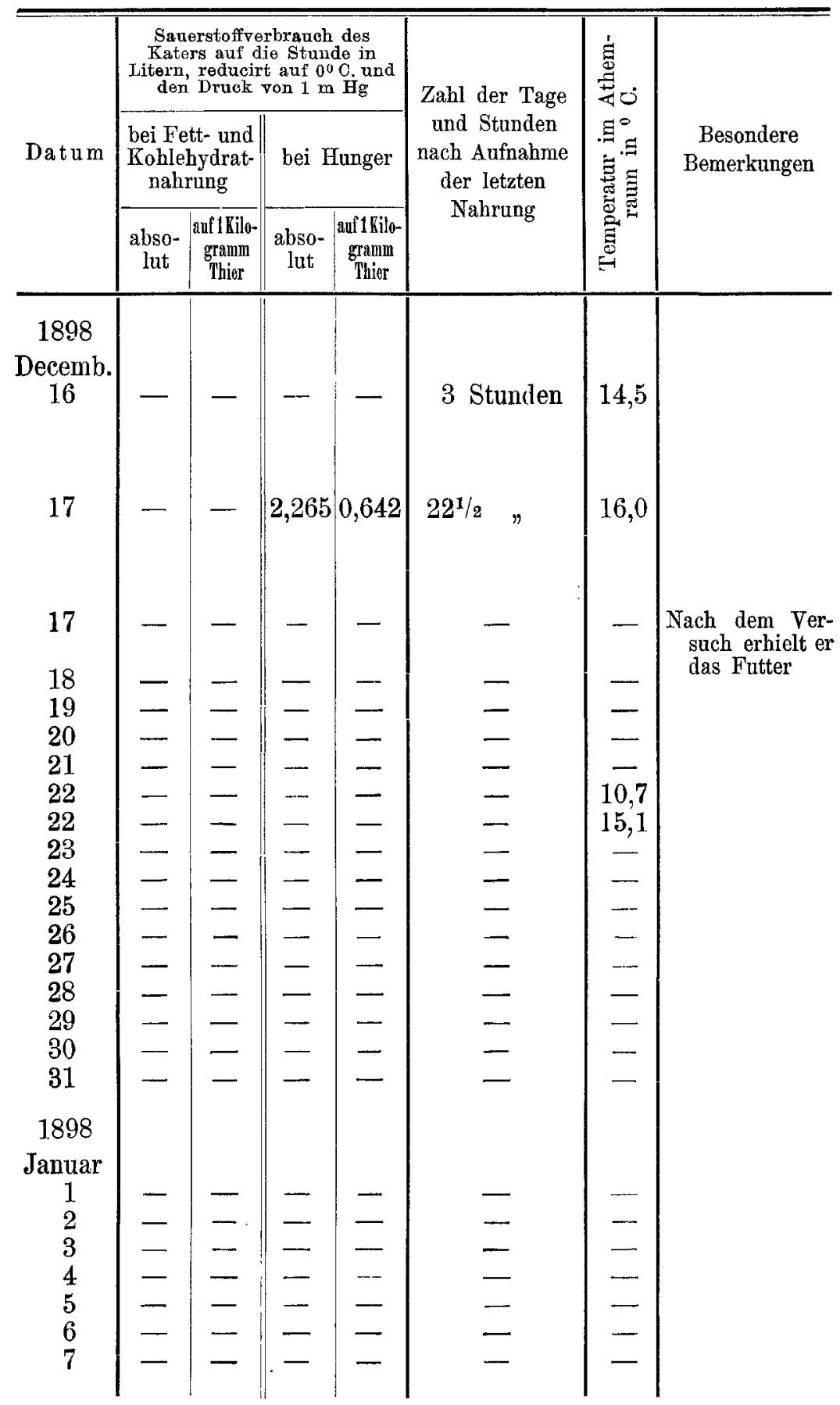


Tabelle VIII (Fortsetzung).

\begin{tabular}{|c|c|c|c|c|c|c|c|c|c|c|}
\hline \multirow{3}{*}{ Datum } & \multirow{3}{*}{ 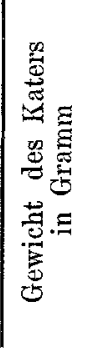 } & \multirow{3}{*}{\multicolumn{3}{|c|}{$\begin{array}{l}\text { Gewicht } \\
\text { und Art des } \\
\text { Futters }\end{array}$}} & \multirow{2}{*}{\multicolumn{2}{|c|}{$\begin{array}{c}\text { Kräfteinhalt } \\
\text { des Futters } \\
\text { in grossen } \\
\text { Wärme- } \\
\text { einheiten }\end{array}$}} & \multicolumn{4}{|c|}{$\begin{array}{c}\text { Sauerstoffverbrauch des } \\
\text { Katers auf die Stunde in } \\
\text { Litern, reducirt auf } 0^{0} \mathrm{C} \text {. und } \\
\text { den Druek von } 1 \mathrm{~m} \text { H }{ }_{g}\end{array}$} \\
\hline & & & & & & & \multicolumn{2}{|c|}{$\begin{array}{c}\text { bei Fleisch- } \\
\text { nahrung }\end{array}$} & \multicolumn{2}{|c|}{$\begin{array}{l}\text { bei Fett- } \\
\text { nahrung }\end{array}$} \\
\hline & & & & & $\begin{array}{c}\text { be- } \\
\text { stimmt }\end{array}$ & to ge- & \begin{tabular}{|c|} 
abso- \\
$\operatorname{lnt}$
\end{tabular} & $\begin{array}{l}\text { auf 1 Kilo- } \\
\text { granmm } \\
\text { Thior }\end{array}$ & $\begin{array}{c}\text { abso- } \\
\text { lut }\end{array}$ & $\begin{array}{l}\text { anf1 Kilo- } \\
\text { granm } \\
\text { Thior }\end{array}$ \\
\hline \multicolumn{11}{|l|}{ Januar } \\
\hline 8 & 3400 & \multicolumn{3}{|c|}{ Hunger } & - & - & — & $\ldots$ & - & - \\
\hline 9 & 3320 & \multicolumn{3}{|c|}{$"$} & - & - & - & 一 & - & - \\
\hline 10 & 3250 & \multirow{2}{*}{\multicolumn{3}{|c|}{$"$}} & - & - & - & - & - & - \\
\hline 11 & 3200 & & & & - & - & - & - & - & - \\
\hline 12 & 3150 & \multicolumn{3}{|c|}{$"$} & - & - & - & - & - & - \\
\hline 13 & 3100 & \multicolumn{3}{|c|}{$"$} & - & - & - & - & - & - \\
\hline 14 & 3050 & \multicolumn{3}{|c|}{$n$} & 一 & - & $\ldots$ & - & - & - \\
\hline 15 & 3000 & \multicolumn{3}{|c|}{$"$} & - & - & - & - & - & - \\
\hline 16 & 2950 & \multicolumn{3}{|c|}{$"$} & - & - & - & - & - & - \\
\hline 17 & 2900 & \multicolumn{3}{|c|}{$n$} & 一 & - & - & $\ldots$ & - & - \\
\hline 18 & 2850 & \multicolumn{3}{|c|}{$n$} & - & - & 一 & - & - & - \\
\hline 19 & 2800 & \multicolumn{3}{|c|}{$n$} & - & - & - & - & $\ldots$ & - \\
\hline 20 & 2750 & \multicolumn{3}{|c|}{$"$} & - & - & - & 一 & - & - \\
\hline 21 & 2700 & \multirow{2}{*}{\multicolumn{3}{|c|}{$"$}} & 一 & - & - & - & - & - \\
\hline 22 & 2650 & & & & 一 & - & - & - & - & - \\
\hline 23 & 2600 & \multicolumn{3}{|c|}{$"$} & 一 & - & - & - & - & 一 \\
\hline 24 & 2700 & \multicolumn{3}{|c|}{$\begin{array}{c}40 \text { Gramm } \\
\text { Schmalz }+ \\
\text { Wasser }\end{array}$} & 380,0 & - & - & - & 1,356 & 0,502 \\
\hline 25 & 2600 & \multicolumn{3}{|c|}{$\begin{array}{c}110,6 \text { Gramm Stärke- } \\
\text { brei }=40 \text { Gramm } \\
\text { Stäke }+20 \text { Gramm } \\
\text { Sehmalz }\end{array}$} & 352,0 & - & - & - & - & - \\
\hline 26 & 2750 & \multicolumn{3}{|c|}{ Milch $1 / 2$ Liter } & - & - & - & - & 一 & - \\
\hline 27 & 2650 & \multirow{2}{*}{\multicolumn{3}{|c|}{$\begin{array}{l}\text { Milch } 1 / 2 \text { Liter } \\
80 \text { Granm Fleiseh }\end{array}$}} & - & - & - & - & - & - \\
\hline 28 & 2750 & & & & — & 88,3 & - & - & - & - \\
\hline 29 & 2800 & 100 & " & & - & 110,3 & - & 一 & - & - \\
\hline 30 & 2900 & 200 & $"$ & & - & 220,7 & - & - & - & - \\
\hline 31 & 2950 & 200 & $"$ & & - & 220,7 & - & - & - & - \\
\hline Februal & & & & & & & & & & \\
\hline 1 & 2950 & 200 & & & - & $220,7 \mid$ & - & - & - & - \\
\hline 2 & 2950 & 400 & $"$ & & 一 & 441,4 & - & -. & - & - \\
\hline 3 & 3150 & 480 & $\eta$ & $"$ & - & 530,0 & - & - & 一 & - \\
\hline 4 & 3200 & 200 & $"$ & & 一 & 220,7 & 2,751 & 0,860 & - & - \\
\hline
\end{tabular}




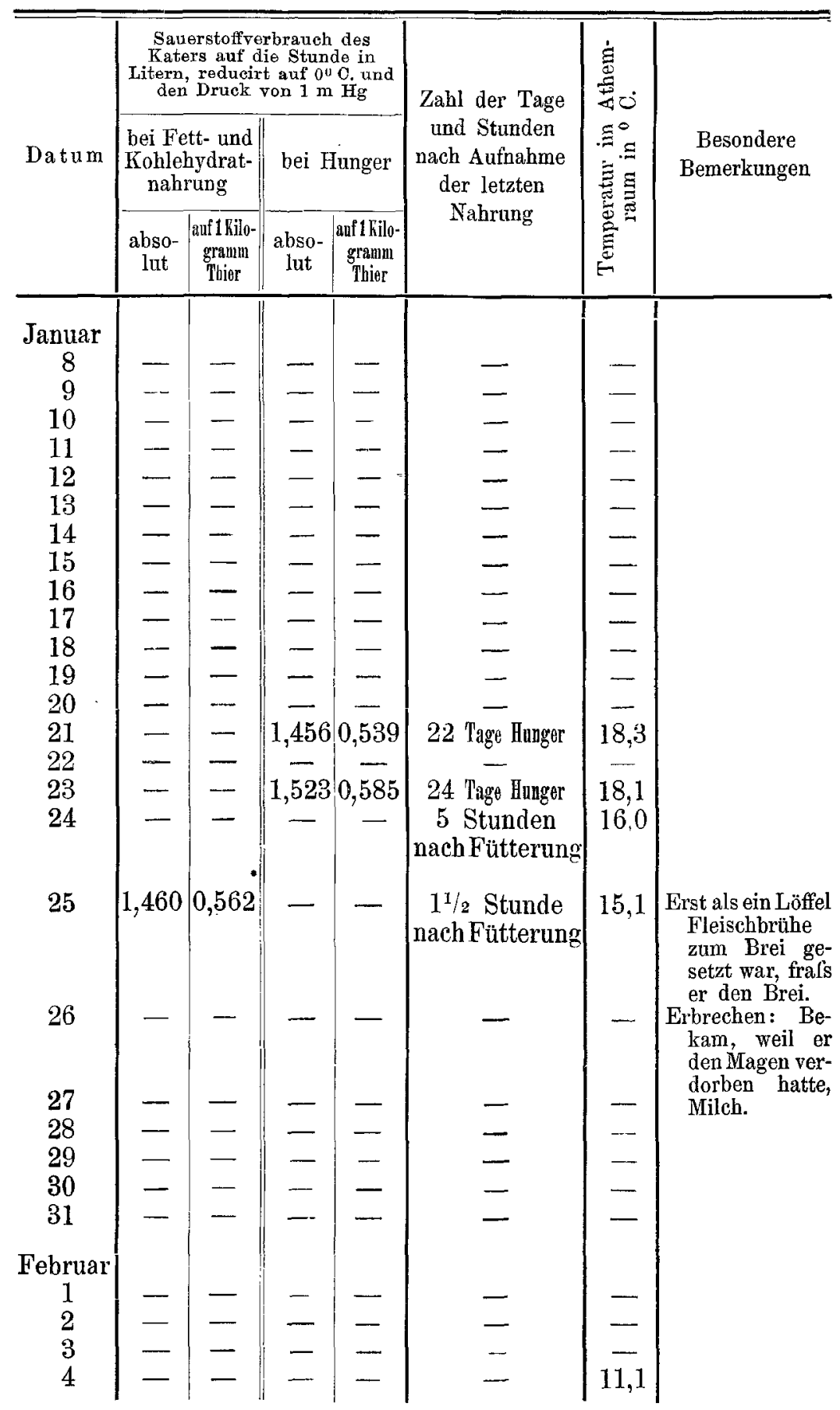


Tabelle VIII (Fortsetzung).

\begin{tabular}{|c|c|c|c|c|c|c|c|c|}
\hline \multirow{3}{*}{ Datum } & \multirow{3}{*}{ 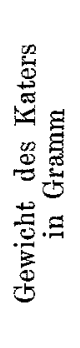 } & \multirow{3}{*}{$\begin{array}{l}\text { Gewicht } \\
\text { und Art des } \\
\text { Futters }\end{array}$} & \multirow{2}{*}{\multicolumn{2}{|c|}{$\begin{array}{l}\text { Kräfteinhalt } \\
\text { des Futters } \\
\text { in grossen } \\
\text { Wärme- } \\
\text { einheiten }\end{array}$}} & \multicolumn{4}{|c|}{$\begin{array}{l}\text { Sauerstoffyerbrauch des } \\
\text { Katers, auf die Stunde in } \\
\text { Litern, reducirt auf } 0^{0} \mathrm{C} \text {. und } \\
\text { den Druek von } 1 \mathrm{~m} \mathrm{Hg}\end{array}$} \\
\hline & & & & & \multicolumn{2}{|c|}{$\begin{array}{c}\text { bei Fleisch- } \\
\text { nahrung }\end{array}$} & \multicolumn{2}{|c|}{$\begin{array}{l}\text { bei Fett- } \\
\text { nahrung }\end{array}$} \\
\hline & & & $\begin{array}{c}\text { be- } \\
\text { stimmt }\end{array}$ & $\begin{array}{c}\text { ge- } \\
\text { sehätzt }\end{array}$ & $\begin{array}{c}\text { abso- } \\
\text { lut }\end{array}$ & $\begin{array}{c}\text { auf1 Kilo- } \\
\text { gramul } \\
\text { Thier }\end{array}$ & $\begin{array}{c}\text { abso- } \\
\text { lut }\end{array}$ & $\begin{array}{l}\text { anf } 1 \text { Kilo- } \\
\text { gramm } \\
\text { Thier }\end{array}$ \\
\hline ebrua & & & & & & & & \\
\hline 5 & 3100 & 200 Gramm Fleiseh & - & $220,7 \mid$ & - & - & - & - \\
\hline 6 & 3050 & $200 \quad " \quad$ & - & 220,7 & - & - & 一 & - \\
\hline 7 & 3050 & 200 & - & 220,7 & - & - & - & — \\
\hline 8 & 3050 & $200 "$ & - & 220,7 & - & - & 一 & - \\
\hline 9 & 3050 & Hunger & - & - & - & - & - & - \\
\hline 10 & 2950 & $"$ & - & 一 & - & - & - & 一 \\
\hline 11 & 2870 & $"$ & 一 & - & - & - & - & - \\
\hline 12 & 2810 & $n$ & - & - & - & - & - & - \\
\hline 13 & 2750 & $"$ & - & 一 & 一 & - & 一 & 一 \\
\hline 14 & 2700 & $\pi$ & - & - & - & - & - & - \\
\hline 14 & 2700 & 200 Gramm Fleiseh & - & 220,7 & 一 & 一 & 一 & - \\
\hline 15 & 2850 & 400 & - & 441,2 & 一 & - & - & - \\
\hline 16 & 3100 & 400 & - & 441,2 & - & — & - & - \\
\hline 17 & 3170 & $470 "$ & - & 518,4 & - & - & 一 & - \\
\hline 18 & 3250 & 450 & - & 496,6 & 1,955 & 0,602 & - & - \\
\hline 19 & 3300 & $460 "$ & - & 507,6 & - & - & - & - \\
\hline 20 & 3350 & $450 "$ & - & 496,6 & 2,235 & 0,667 & - & 一 \\
\hline 21 & 3420 & $460 " n$ & - & 507,6 & $\vec{\nabla}$ & - & 一 & 一 \\
\hline 22 & 3450 & Hunger & - & -1 & 1,785 & 0,517 & - & 一 \\
\hline 23 & 3250 & $n$ & 一 & - & - & - & - & - \\
\hline 24 & 3150 & $"$ & - & - & - & - & - & 一 \\
\hline 25 & 3000 & 300 Gramm Fleisch & - & 330,9 & 1,984 & 0,661 & - & - \\
\hline 26 & 3050 & Hunger & - & - & - & - & - & - \\
\hline 27 & 3000 & $\eta$ & - & 一 & - & - & - & - \\
\hline 28 & 2920 & $n$ & - & - & - & - & - & 一 \\
\hline März & & & & & & & & \\
\hline 1 & 2850 & Hunger & - & 一 & 一 & - & - & - \\
\hline 2 & 2800 & $n$ & - & 一 & - & - & - & - \\
\hline 3 & 2750 & & - & 一 & - & - & - & - \\
\hline 4 & 2700 & 305 Gramm Pleiseh & - & 336,4 & 2,217 & 0,821 & - & 一 \\
\hline 5 & 2800 & Hunger & - & - & - & - & - & 一 \\
\hline 6 & 2700 & 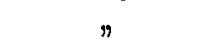 & - & - & - & - & - & 一 \\
\hline 7 & 2650 & $n$ & - & - & - & 一 & - & - \\
\hline 8 & 2600 & $n$ & - & 一 & - & 一 & - & - \\
\hline 8 & 2600 & 322 Gramm Fleiseh & - & 355,2 & 1,890 & 0,727 & - & 一 \\
\hline 8 & 一 & $78, "$ & - & 86,0 & - & 一 & - & - \\
\hline
\end{tabular}




\begin{tabular}{|c|c|c|c|c|c|c|c|}
\hline \multirow{3}{*}{ Datum } & \multicolumn{4}{|c|}{$\begin{array}{l}\text { Sauverstoffverbrauch des } \\
\text { Katers auf die Stunde in } \\
\text { Litern, reducirt auf } 0^{\circ} \mathrm{C} \text {. und } \\
\text { den Druck von } 1 \mathrm{~m} \mathrm{Hg}\end{array}$} & \multirow{3}{*}{$\begin{array}{l}\text { Zahl der Tage } \\
\text { und Stunden } \\
\text { nach Aufnahme } \\
\text { der letzten } \\
\text { Nahrung }\end{array}$} & \multirow{3}{*}{ 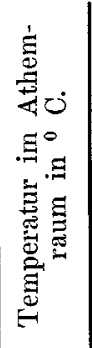 } & \multirow{3}{*}{$\begin{array}{c}\text { Besondere } \\
\text { Bemerkungen }\end{array}$} \\
\hline & \multicolumn{2}{|c|}{$\begin{array}{l}\text { bei Fett- und } \\
\text { Kohlehydrat- } \\
\text { nahrung }\end{array}$} & \multicolumn{2}{|c|}{ bei Hunger } & & & \\
\hline & $\begin{array}{l}\text { abso- } \\
\text { lut }\end{array}$ & $\begin{array}{l}\text { auf } 1 \text { Kilo- } \\
\text { gramum } \\
\text { Thier }\end{array}$ & $\begin{array}{c}\text { abso- } \\
\text { lut }\end{array}$ & $\begin{array}{c}\text { auf 1 Filo- } \\
\text { gramm } \\
\text { Thier }\end{array}$ & & & \\
\hline \multicolumn{8}{|l|}{ Februar } \\
\hline 5 & - & - & 一 & - & 一 & - & \\
\hline 6 & - & - & 一 & - & 一 & 一 & \\
\hline 7 & - & - & - & - & - & 一 & \\
\hline 8 & 一 & - & - & - & - & - & \\
\hline 9 & 一 & - & - & - & - & 一 & \\
\hline 10 & - & - & - & - & 一 & - & \\
\hline 11 & - & - & - & 一 & - & - & \\
\hline 12 & - & - & - & - & - & 一 & \\
\hline 13 & - & - & - & $\cdots$ & 一 & - & \\
\hline 14 & - & - & 1,551 & 0,575 & 5 Tage Hunger & 18,3 & \\
\hline 14 & - & 一 & - & - & - & - & $\begin{array}{l}\text { Nach dem Athem- } \\
\text { versuche. }\end{array}$ \\
\hline 15 & - & - & - & - & - & - & \\
\hline 16 & - & - & - & - & - & - & \\
\hline 17 & - & - & - & - & - & - & \\
\hline 18 & - & - & - & - & - & 18,3 & \\
\hline 19 & 一 & 一 & - & - & - & - & \\
\hline 20 & - & - & - & - & 一 & 18,0 & \\
\hline 21 & - & - & - & - & - & - & \\
\hline 22 & - & - & - & - & - & 17,5 & \\
\hline 23 & - & - & 1,638 & 0,504 & 24 Stunden & 16,5 & \\
\hline 24 & - & - & . & - & - & - & \\
\hline 25 & - & - & - & - & $3 / 4$ Stunde & 14,5 & \\
\hline 26 & - & - & - & - & - & - & \\
\hline 27 & - & - & -- & - & - & - & \\
\hline 28 & - & - & - & - & 一 & - & \\
\hline \multicolumn{8}{|l|}{ März } \\
\hline 1 & - & - & 一 & - & - & 一 & \\
\hline 2 & - & - & - & - & - & - & \\
\hline 3 & - & - & - & - & - & - & \\
\hline 4 & - & - & 一 & - & 0,0 & 14,5 & \\
\hline 5 & - & - & - & - & - & - & \\
\hline 6 & - & - & 一 & - & - & - & \\
\hline 7 & - & - & - & - & - & - & \\
\hline 8 & 一 & - & 1,579 & 0,607 & 3 Tage Hunger & 13,1 & \\
\hline 8 & - & - & - & - & $1 / 4$ Stunde & - & \\
\hline 8 & 一 & - & - & - & - & 13,7 & $\begin{array}{l}\text { Nach dem Athem- } \\
\text { versuche. }\end{array}$ \\
\hline
\end{tabular}


Tabelle VIII (Fortsetzung).

\begin{tabular}{|c|c|c|c|c|c|c|c|c|}
\hline \multirow{3}{*}{ Datum } & \multirow{3}{*}{ 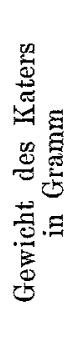 } & \multirow{3}{*}{$\begin{array}{l}\text { Gewicht } \\
\text { und Art des } \\
\text { Futters }\end{array}$} & \multirow{2}{*}{\multicolumn{2}{|c|}{$\begin{array}{l}\text { Kräfteinhalt } \\
\text { des Futters } \\
\text { in grossen } \\
\text { Wärme- } \\
\text { einheiten }\end{array}$}} & \multicolumn{4}{|c|}{$\begin{array}{l}\text { Sauerstoffiverbrauch des } \\
\text { Katers auf die Stunde in } \\
\text { Litern, redueirt auf } 0^{0} \mathrm{C} \text {. und } \\
\text { den Druck von } 1 \mathrm{~m} \mathrm{Bg}\end{array}$} \\
\hline & & & & & \multicolumn{2}{|c|}{$\begin{array}{l}\text { bei Fleisch- } \\
\text { nahrung }\end{array}$} & \multicolumn{2}{|c|}{$\begin{array}{l}\text { bei Fett- } \\
\text { nahrung }\end{array}$} \\
\hline & & & $\mid \begin{array}{c}\text { be- } \\
\text { stimmt }\end{array}$ & $\begin{array}{c}\text { ge- } \\
\text { schätzt }\end{array}$ & $\begin{array}{l}\text { abso- } \\
\text { lut }\end{array}$ & 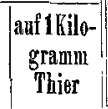 & $\begin{array}{l}\text { abso- } \\
\text { lut }\end{array}$ & $\begin{array}{c}\text { anf1 Kilo } \\
\text { gramm } \\
\text { Thier }\end{array}$ \\
\hline März & & & & & & & & \\
\hline 9 & 2800 & 450 & - & 496,6 & -- & - & - & 一 \\
\hline 10 & 2850 & 470 & - & 518,4 & - & - & 一 & - \\
\hline 11 & 2950 & 430 & 一 & 474,3 & - & - & 一 & - \\
\hline 12 & 3000 & $340 "$ & - & 375,0 & 一 & 一 & - & - \\
\hline 13 & 3000 & Hunger & 一 & - & - & - & - & - \\
\hline 14 & 2850 & $n$ & - & 一 & - & - & - & - \\
\hline 15 & 2800 & $"$ & - & 一 & 一 & - & - & - \\
\hline 16 & 2750 & $"$ & - & 一 & 一 & - & - & - \\
\hline 17 & 2700 & & - & - & - & - & - & - \\
\hline 18 & 2650 & $\begin{array}{c}175 \text { framm Reisbrei } \\
=40 \text { tramm Reis } \\
13 \text { Gramm Butter }\end{array}$ & 260 & - & - & - & 一 & - \\
\hline 19 & 2650 & 50 Gramm Fleisch & - & 55,1 & - & - & - & - \\
\hline 20 & 2600 & 50 & 一 & 55,1 & - & - & - & - \\
\hline 21 & 2550 & $50 "$ & - & 55,1 & - & - & 一 & - \\
\hline 22 & 2520 & 50 & 一 & 55,1 & - & - & - & - \\
\hline 23 & 2500 & 100 & - & 110,3 & - & - & - & - \\
\hline 24 & 2500 & $\begin{array}{l}169 \text { GrammReishrei } \\
=36,7 \text { Gramm } \\
\text { Reis }+12,2 \\
\text { Gramm Butter }\end{array}$ & 241 & - & 一 & $\cdots$ & - & - \\
\hline 25 & 2580 & 170 Gramm Heischl & 一 & 187,5 & 1,737 & 0,673 & - & $\ddot{-}$ \\
\hline 26 & 2600 & Hunger & - & - & - & - & - & - \\
\hline 27 & 2550 & 170 Gramm Heisch & 一 & 187,5 & 1,964 & 0,770 & - & 一 \\
\hline 27 & - & $30 \quad " \quad "$ & - & 33,1 & - & - & - & 一 \\
\hline 28 & 2550 & Hunger & - & - & 一 & - & - & - \\
\hline 29 & 2520 & $\begin{array}{l}219 \text { Gramm Reishrei } \\
=60 \text { Gramm Reis } \\
\text { obne Fett }\end{array}$ & 210,6 & - & - & - & 一 & - \\
\hline 29 & - & 100 Gramm Fleisch & - & - & - & - & - & - \\
\hline 30 & 2600 & Hunger & - & 一 & - & - & - & - \\
\hline 31 & 2550 & 200 Gramm Fleiseh & - & 220,7 & 1,851 & 0,726 & - & 一 \\
\hline 31 & - & $200 " n$ & 一 & 220,7 & - & - & - & - \\
\hline
\end{tabular}




\begin{tabular}{|c|c|c|c|c|c|c|c|}
\hline \multirow{3}{*}{ Datum } & \multicolumn{4}{|c|}{$\begin{array}{c}\text { Sauerstoffverbrauch des } \\
\text { Katers auf die Stunde in } \\
\text { Litern, reducirt auf } 0^{0} \mathrm{C} \text {, und } \\
\text { den Druek von } 1 \mathrm{~m} \mathrm{Hg}\end{array}$} & \multirow{3}{*}{$\begin{array}{c}\text { Zahl der Tage } \\
\text { und Stunden } \\
\text { nach Aufnahme } \\
\text { der letzten } \\
\text { Nahrung }\end{array}$} & \multirow{3}{*}{ 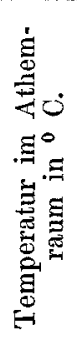 } & \multirow{3}{*}{$\begin{array}{c}\text { Besondere } \\
\text { Bemerkungen }\end{array}$} \\
\hline & \multicolumn{2}{|c|}{$\begin{array}{c}\text { bei Fett- und } \\
\text { Kohlehydrat- } \\
\text { nahrung }\end{array}$} & \multicolumn{2}{|c|}{ bei Hunger } & & & \\
\hline & $\begin{array}{c}\text { abso- } \\
\text { lnt }\end{array}$ & $\mid \begin{array}{c}\text { auf } 1 \text { Kilo- } \\
\text { gramma } \\
\text { Thier }\end{array}$ & $\begin{array}{l}\text { abso- } \\
\text { lut }\end{array}$ & $\mid \begin{array}{c}\text { auf I kilo } \\
\text { gramm } \\
\text { Thier }\end{array}$ & & & \\
\hline \multicolumn{8}{|l|}{ März } \\
\hline 9 & - & - & - & - & 一 & - & \\
\hline 10 & - & - & 一 & - & - & - & \\
\hline 11 & 一 & - & - & - & - & 一 & \\
\hline 12 & 一 & 一 & - & - & - & - & \\
\hline 13 & - & - & 1,348 & 0,449 & $\begin{array}{l}11 / 2 \text { Tage } \\
\text { seit letzter } \\
\text { Fütterung }\end{array}$ & 18,0 & \\
\hline 14 & - & - & - & - & - & - & \\
\hline 15 & - & -- & - & - & - & $\ldots$ & \\
\hline 16 & - & $\ldots$ & - & - & - & - & \\
\hline 17 & - & - & 一 & 一 & - & - & \\
\hline 18 & 1,278 & 0,482 & - & - & $3^{3} / 4$ Stunden & 16,6 & \\
\hline 19 & - & - & - & - & - & - & \\
\hline 20 & 一 & - & - & 一 & 一 & - & \\
\hline 21 & 一 & - & - & - & - & - & \\
\hline 22 & - & - & - & - & - & - & \\
\hline 23 & 一 & - & - & - & - & - & \\
\hline 24 & 1,435 & 0,574 & - & - & 4 Stunden & 16,5 & \\
\hline 25 & 一 & - & 一 & - & $2^{1 / 2}$ Stunden & 14,9 & \\
\hline 26 & - & 一 & - & - & - & $\overline{-}$ & \\
\hline 27 & - & - & - & 一 & $2^{1 / 2}$ Stunden & 15,1 & \\
\hline 27 & - & - & - & - & - & - & $\begin{array}{l}\text { Nach dem Athem- } \\
\text { versuche. }\end{array}$ \\
\hline 28 & - & - & - & - & - & - & \\
\hline 29 & 1,112 & 0,441 & 一 & - & 2 Stunden & 15,4 & \\
\hline 29 & 一 & - & - & - & - & - & $\begin{array}{l}\text { Nach dem Athem- } \\
\text { versuche. }\end{array}$ \\
\hline 30 & - & 一 & 一 & - & - & - & \\
\hline 31 & - & - & 一 & - & $2^{1 / 4}$ Stunden & 15,7 & \\
\hline 31 & 一 & - & - & - & - & - & $\begin{array}{l}\text { Nach dem Athem- } \\
\text { versuche. }\end{array}$ \\
\hline
\end{tabular}


Tabelle VIII (Fortsetzung).

\begin{tabular}{|c|c|c|c|c|c|c|c|c|}
\hline \multirow{3}{*}{ Datum } & \multirow{3}{*}{ 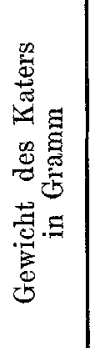 } & \multirow{3}{*}{$\begin{array}{l}\text { Gewicht } \\
\text { und Art des } \\
\text { Futters }\end{array}$} & \multirow{2}{*}{\multicolumn{2}{|c|}{$\begin{array}{c}\text { Kräftteinhalt } \\
\text { des Futters } \\
\text { in grossen } \\
\text { Wärme- } \\
\text { einheiten }\end{array}$}} & \multicolumn{4}{|c|}{$\begin{array}{l}\text { Sauerstoffrexbrauch des } \\
\text { Katers auf die Stunde in } \\
\text { Litern, reducirt auf } 0^{0} \mathrm{O} \text {. und } \\
\text { den Druck von } 1 \mathrm{~m} \mathrm{Hg}\end{array}$} \\
\hline & & & & & \multicolumn{2}{|c|}{$\begin{array}{c}\text { bei Fleisch- } \\
\text { nahrung }\end{array}$} & \multicolumn{2}{|c|}{$\begin{array}{l}\text { bei Fett- } \\
\text { nahrung }\end{array}$} \\
\hline & & & $\begin{array}{l}\text { be- } \\
\text { stimmt }\end{array}$ & tê- & $\begin{array}{l}\text { abso- } \\
\text { lut }\end{array}$ & $\begin{array}{c}\text { guf } 1 \text { Kilo- } \\
\text { gramm } \\
\text { Thiser }\end{array}$ & $\begin{array}{l}\text { abso- } \\
\text { lut }\end{array}$ & $\begin{array}{c}\text { anf1 Kilo- } \\
\text { grumm } \\
\text { Thier }\end{array}$ \\
\hline \multicolumn{9}{|l|}{ April } \\
\hline 1 & 2700 & 400 Gramm Pleisch & - & 441,2 & - & - & 一 & 一 \\
\hline 2 & 2800 & $200 \pi$ & - & 220,7 & - & - & - & - \\
\hline$\overline{3}$ & 2800 & 400 & - & 441,4 & - & - & - & - \\
\hline 4 & 2950 & Hunger & - & - & - & - & 一 & - \\
\hline 5 & 2850 & $"$ & - & - & - & 一 & 一 & - \\
\hline 6 & 2770 & $n$ & 一 & - & - & - & - & 一 \\
\hline 7 & 2700 & $\begin{array}{l}20 \text { Gramin Butter } \\
105 \text { Gramm Reishrei } \\
=43 \text { Gramm Reis }\end{array}$ & 335,5 & - & - & - & - & - \\
\hline 7 & - & 200 Gramm Pleiseli & - & 220,7 & 一 & - & - & 一 \\
\hline 8 & 2800 & Hunger & - & - & 一 & - & - & - \\
\hline 9 & 2700 & $n$ & - & - & - & - & - & - \\
\hline 10 & 2650 & $\begin{array}{l}100 \text { Gramm Reisbrei } \\
=30 \text { Gramm Reis } \\
+3 \text { Gramm Schmalz } \\
\text { Hunoer }\end{array}$ & 123,2 & 一 & - & - & -- & -- \\
\hline $\begin{array}{l}11 \\
12\end{array}$ & 2500 & $\begin{array}{l}\text { Aunger } \\
\text { 193 Aramm Reisbrei }\end{array}$ & $2 \overline{200}$ & - & - & - & - & - \\
\hline & & $=57$ Gramm Reis & & & & & & \\
\hline 13 & 2500 & $\begin{array}{l}200 \text { Gramm } \\
\text { Fleischbrei }\end{array}$ & - & 220,7 & 1,372 & 0,549 & 一 & - \\
\hline 13 & 2500 & $\begin{array}{l}200 \text { Gramm } \\
\text { Fleischbrei }\end{array}$ & 一 & 220,7 & 1,328 & 0,581 & - & - \\
\hline 14 & 2500 & Hunger & - & - & - & - & - & - \\
\hline 14 & - & 300 Gramm Fleiseh & - & 330,9 & 一 & 一 & - & - \\
\hline 15 & 2600 & 450 & - & 496,6 & - & - & - & - \\
\hline 16 & 2750 & $410 " n$ & - & 452,2 & - & - & - & 一 \\
\hline 17 & 2850 & $430 "$ & - & 474,3 & - & - & 一 & 一 \\
\hline 18 & 2950 & $400 "$ & - & 441,2 & - & - & - & - \\
\hline 19 & 3050 & $200 " n$ & - & 220,7 & - & 一 & - & - \\
\hline 20 & 3000 & Hunger" & 一 & - & - & - & - & - \\
\hline 21 & 2850 & & 一 & - & - & - & - & - \\
\hline 22 & 2770 & & $\ldots$ & - & - & - & - & 一 \\
\hline 23 & 2720 & 420 Gramm Fleisch & - & 463,5 & - & - & - & $=$ \\
\hline 24 & 2850 & $400 " n$ & - & 441,4 & - & - & - & - \\
\hline
\end{tabular}




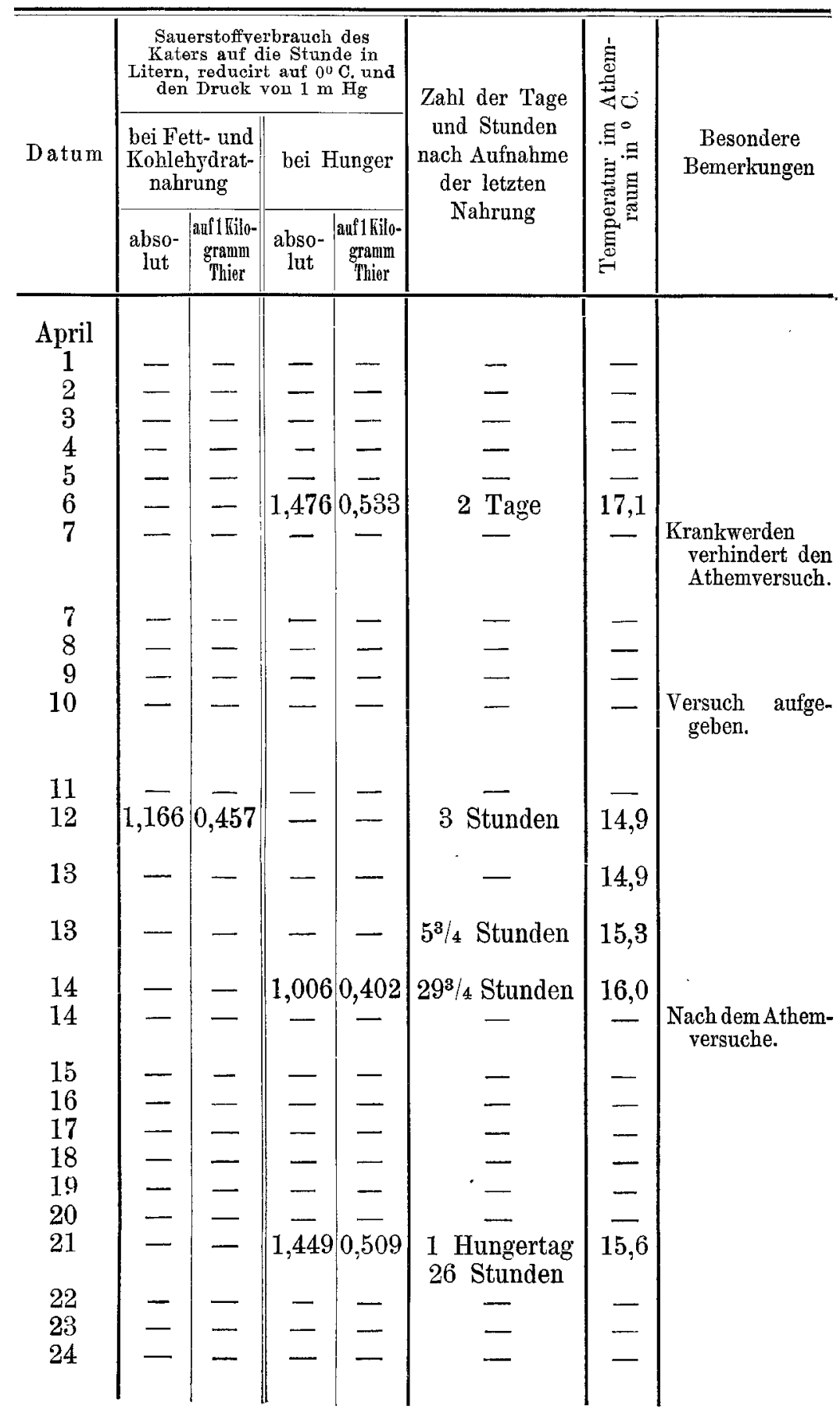


Tabelle VIII (Fortsetzung).

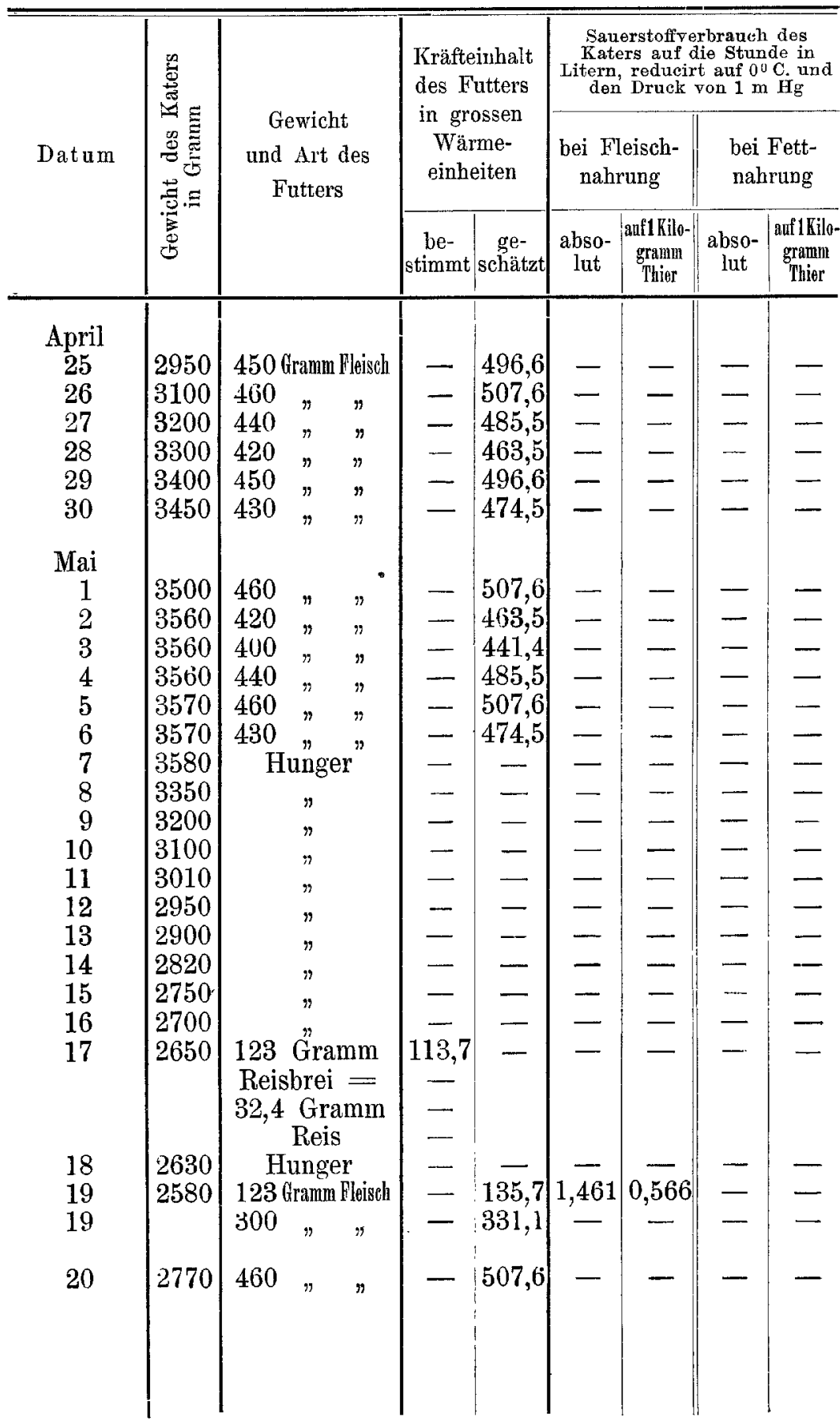




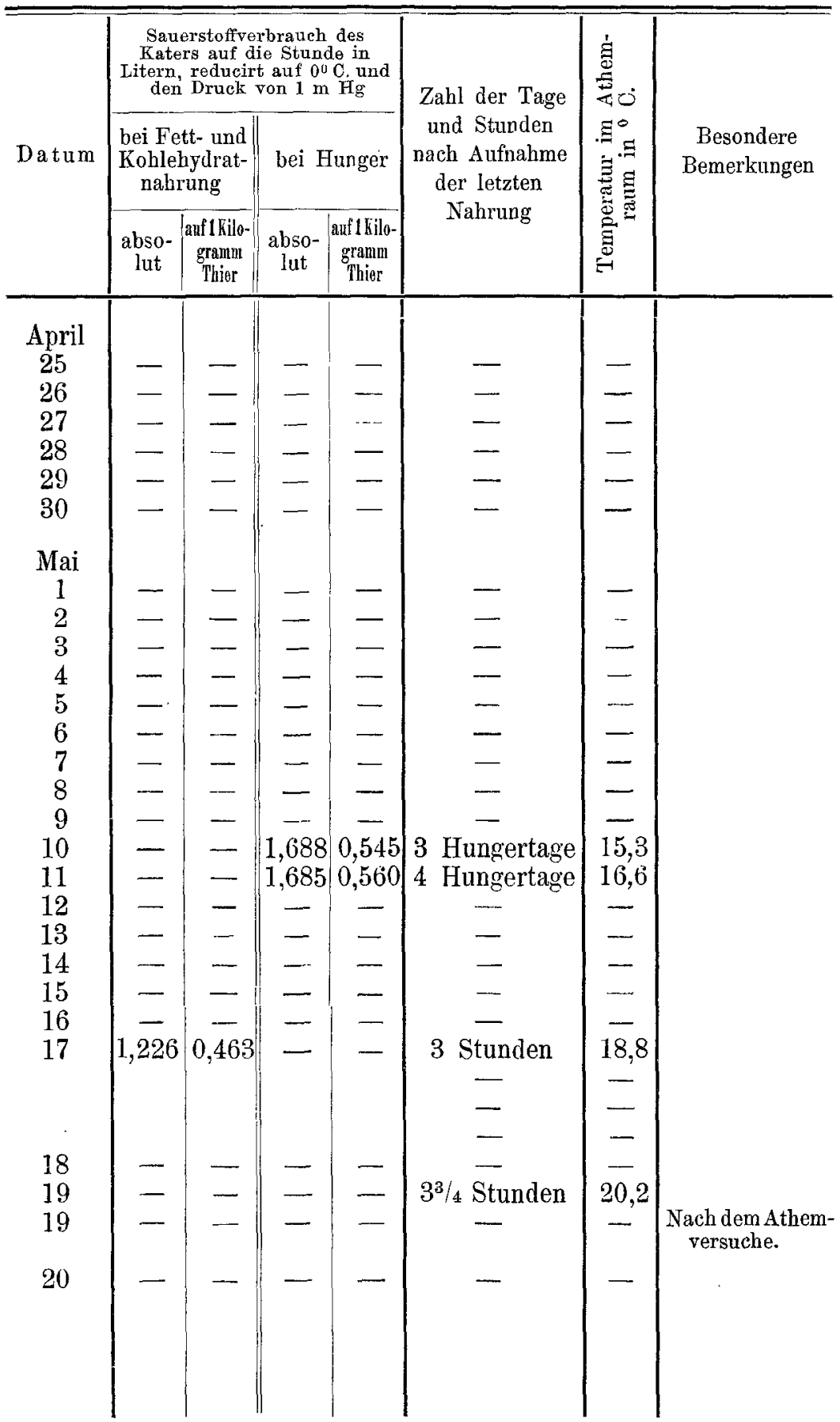

E. Pflūger, Arehiv für Physiologie. Bd. 7 `. 
Aus der Tabelle VIII leite ich nun zur Erleichterung der Ergebnisse folgende kleineren Tabellen ab:

\section{Tabelle IX.}

Vollkommene Entziehung der Nahrung.

\begin{tabular}{|c|c|c|c|}
\hline \multirow{2}{*}{$\begin{array}{l}\text { Gewicht des } \\
\text { Thieres }\end{array}$} & \multicolumn{2}{|c|}{$\begin{array}{c}\text { Sauerstoffiverbrauch anf } 1 \text { Stunde } \\
\text { in Litern reducirt auf } 0^{\circ} \mathrm{C} \text {. und den } \\
\text { Druck von } 1 \mathrm{~m} \mathrm{Hg}\end{array}$} & \multirow{2}{*}{$\begin{array}{c}\text { Temperatur } \\
\text { im Athemraum in } \\
0^{\circ} \mathrm{C} .\end{array}$} \\
\hline & absolut & 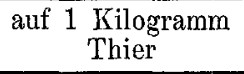 & \\
\hline 2700 & 1,456 & 0,539 & 18,3 \\
\hline 2600 & 1,523 & 0,585 & 18,1 \\
\hline 2700 & 1,551 & 0,575 & 18,3 \\
\hline 3250 & 1,638 & 0,504 & 16,5 \\
\hline 2600 & 1,579 & 0,607 & 13,1 \\
\hline 3000 & 1,348 & 0,449 & 18,0 \\
\hline 2770 & 1,476 & 0,533 & 17,1 \\
\hline 2500 & 1,000 & 0,402 & 16,0 \\
\hline 2850 & 1,449 & 0,509 & 15,6 \\
\hline 3100 & 1,688 & 0,545 & 15,3 \\
\hline 3010 & 1,685 & 0,560 & 16,6 \\
\hline Summe 31080 & 16,399 & 5,808 & 182,9 \\
\hline Mittel 2825 & 1,491 & 0,528 & $16,6^{\circ} \mathrm{C}$. \\
\hline
\end{tabular}

Tabelle X.

Fleischnahrung in ungenügender Menge.

\begin{tabular}{|c|c|c|c|c|}
\hline \multirow{2}{*}{$\begin{array}{c}\text { Gewicht } \\
\text { des Katers in } \\
\text { Gramm }\end{array}$} & \multicolumn{2}{|c|}{$\begin{array}{l}\text { Sauerstoffrerbrauch auf } 1 \mathrm{Stunde} \\
\text { in Litern reducirt auf } 0^{\circ} \mathrm{C} \text {. and } \\
\text { den Druck von } 1 \mathrm{~m} \mathrm{Hg}\end{array}$} & \multirow{2}{*}{$\begin{array}{l}\text { Kraftinhalt } \\
\text { des gefütter- } \\
\text { ten Fleisches } \\
\text { in grossen } \\
\text { Wärme- } \\
\text { einheiten }\end{array}$} & \multirow{2}{*}{$\begin{array}{l}\text { Temperatur } \\
\text { im Athem- } \\
\text { raum in } \\
0^{\circ} \mathrm{C} \text {. }\end{array}$} \\
\hline & absolut & 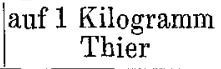 & & \\
\hline 3200 & 2,751 & 0,860 & 220,7 & 11,1 \\
\hline 2580 & 1,737 & 0,673 & 187,5 & 14,9 \\
\hline 2550 & 1,964 & 0,770 & 187,5 & 15,1 \\
\hline 2550 & 1,851 & 0,726 & 220,7 & 15,7 \\
\hline 2500 & 1,372 & 0,549 & 220,7 & 14,9 \\
\hline 25 & 1,328 & 0,531 & 220,7 & 15,3 \\
\hline 2580 & 1,461 & 0,566 & 135,7 & 20,2 \\
\hline Summe 18460 & 12,464 & 4,675 & 1393,5 & 107,2 \\
\hline Mittel $\quad 2637$ & 1,781 & 0,668 & 199,0 & $15,3^{\circ} \mathrm{C}$ \\
\hline
\end{tabular}


Tabelle XI.

Fleischnahrung. Erhaltungsfutter

\begin{tabular}{|c|c|c|c|c|}
\hline \multirow{2}{*}{$\begin{array}{l}\text { Gewicht } \\
\text { des Katers in } \\
\text { Gramm }\end{array}$} & \multicolumn{2}{|c|}{$\begin{array}{l}\text { Sauerstoffiverbrauch auf } 1 \text { Stunde } \\
\text { in Litern reducirt auf } 0^{\circ} \mathrm{C} \text {. und } \\
\text { den Druck von } 1 \mathrm{~m} \mathrm{Hg}\end{array}$} & \multirow{2}{*}{$\begin{array}{l}\text { Kraftinhalt } \\
\text { des gefütter- } \\
\text { ten Fleisches } \\
\text { in grossen } \\
\text { Wärme- } \\
\text { einheiten }\end{array}$} & \multirow{2}{*}{$\begin{array}{l}\text { Temperatur } \\
\text { im Athem- } \\
\text { raum } \\
\text { in } 0^{\circ} \mathrm{C} \text {. }\end{array}$} \\
\hline & absolut & $\begin{array}{c}\text { auf } 1 \text { Kilogramm } \\
\text { Thier }\end{array}$ & & \\
\hline 3530 & 2,492 & 0,706 & 334,2 & 14,5 \\
\hline 3530 & 2,265 & 0,642 & 334,2 & 16,0 \\
\hline Summe 7060 & 4,757 & 1,348 & 668,4 & 30,5 \\
\hline Mittel 3530 & 2,378 & 0,674 & 334,2 & $15,2^{\circ} \mathrm{C}$ \\
\hline
\end{tabular}

Tabelle XII.

Fleischnahrung in grösster Menge.

\begin{tabular}{|c|c|c|c|c|}
\hline \multirow{2}{*}{$\begin{array}{c}\text { Gewicht } \\
\text { des Katers in } \\
\text { Gramm }\end{array}$} & \multicolumn{2}{|c|}{$\begin{array}{l}\text { Sauerstoffverbrauch auf } 1 \mathrm{Stunde} \\
\text { in Litern reducirt auf } 0^{\circ} \mathrm{C} \text {. und } \\
\text { den Druck von } 1 \mathrm{~m} \mathrm{Hg}\end{array}$} & \multirow{2}{*}{\begin{tabular}{|c|} 
Kraftinhalt \\
des gefütter- \\
ten Fleisches \\
in grossen \\
Wärme- \\
einheiten
\end{tabular}} & \multirow{2}{*}{$\begin{array}{l}\text { Temperatur- } \\
\text { im Athem- } \\
\text { raum } \\
\text { in } 0^{\circ} \mathrm{C} \text {. }\end{array}$} \\
\hline & absolut & $\begin{array}{c}\text { auf } 1 \text { Kilogramm } \\
\text { Thier }\end{array}$ & & \\
\hline 4200 & 2,813 & 0,670 & 530,0 & 10,7 \\
\hline 4200 & 2,657 & 0,633 & 530,0 & 15,1 \\
\hline 3250 & 1,955 & 0,602 & 496,6 & 18,3 \\
\hline 3350 & 2,235 & 0,667 & 496,6 & 18,0 \\
\hline 3000 & 1,984 & 0,661 & 380,9 & 14,5 \\
\hline 2700 & 2,217 & 0,821 & 336,4 & 14,5 \\
\hline 2600 & 1,890 & 0,727 & 355,2 & 13,7 \\
\hline Summe 23300 & 15,751 & 4,781 & 3075,7 & 104,8 \\
\hline Mittèl $\quad 3,329$ & 2,250 & 0,683 & 439 & $15,0^{\circ} \mathrm{C}$ \\
\hline
\end{tabular}

Fassen wir die Tabellen, vor Allem Tabelle XIII. in das Auge, so zeigt sich zuerst, dass der Stoffwechsel a m kleinsten ist, wenn das Thier keine Nahrung erhält oder Fett und Kohlehydrate ohne Fleisch, am grössten bei Fleischnahrung.

Betrachten wir den Einfluss, den die Fleischnahrung ausübt, wenn sie in verschiedener Menge gefüttert wird, so ergibt sich die auffallende Thatsache, dass die Höhe des Stoffwechsels, wenn er auf die Einheit des Körpergewichtes bezogen wird, immer nahezu denselben Werth behauptet, gleichgültig, ob das Thier so viel 
Tabelle XIII.

Nahrung von Kohlehydraten und Fett.

\begin{tabular}{|c|c|c|c|c|}
\hline \multirow{2}{*}{$\begin{array}{l}\text { Gewicht } \\
\text { des Katers in } \\
\text { Gramm }\end{array}$} & \multicolumn{2}{|c|}{$\begin{array}{l}\text { Sauerstoffverbrauch auf } 1 \text { Stunde } \\
\text { in Litern, reducirt auf } 0^{\circ} \mathrm{C} \text {. und } \\
\text { den Druck von } 1 \mathrm{~m} \mathrm{Hg}\end{array}$} & \multirow{2}{*}{$\begin{array}{l}\text { Kraftinhalt } \\
\text { der gefutter- } \\
\text { ten Nahrung } \\
\text { in grossen } \\
\text { Wärme- } \\
\text { einheiten } \\
\end{array}$} & \multirow{2}{*}{$\begin{array}{l}\text { Temperatur } \\
\text { im Athem- } \\
\text { raum } \\
\text { in } 0^{\circ} \mathrm{C} \text {. }\end{array}$} \\
\hline & absolut & $\begin{array}{c}\text { auf } 1 \text { Kilogramm } \\
\text { Thier }\end{array}$ & & \\
\hline 2700 & 1,356 & 0,502 & 380 & 16,0 \\
\hline 2600 & $1,4 \mathrm{~b} 0$ & 0,562 & 352 & 15,1 \\
\hline 2650 & 1,278 & 0,482 & 260 & 16,6 \\
\hline 2500 & 1,435 & 0,574 & 241 & 16,5 \\
\hline 2520 & 1,112 & 0,441 & 210,6 & 15,4 \\
\hline 2550 & 1,166 & 0,457 & $200^{\prime}$ & 14,9 \\
\hline 2650 & 1,226 & 0,463 & 113,7 & 18,8 \\
\hline Summe 15470 & 7,677 & 2,979 & 1377,3 & 97,3 \\
\hline Mittel 2578 & 1,279 & 0,496 & 229,0 & 16,2 \\
\hline
\end{tabular}

Erster Versuch, weil Nahrung nur Fett, nicht zum Mittel verwerthet.

General-Tabelle XIV.

\begin{tabular}{|c|c|c|c|c|c|}
\hline & \multicolumn{5}{|c|}{ Der Kater erhält als Nahrung } \\
\hline & $\begin{array}{c}\text { Kein } \\
\text { Futter }\end{array}$ & $\begin{array}{l}\text { Ungenügende } \\
\text { Fleisch- } \\
\text { mengen }= \\
\text { 199 Wärme- } \\
\text { einheiten }\end{array}$ & $\begin{array}{c}\text { Gerade } \\
\text { genügende } \\
\text { Fleisch- } \\
\text { mengen }= \\
334,2 \text { grosse } \\
\text { Wärme- } \\
\text { einheiten }\end{array}$ & $\begin{array}{l}\text { Ueber- } \\
\text { schüssige } \\
\text { Fleisch- } \\
\text { mengen }= \\
439 \text { grosse } \\
\text { Wärme- } \\
\text { einheiten }\end{array}$ & $\begin{array}{c}\text { Fett }+ \text { Kohle- } \\
\text { hydrat }=229 \\
\text { grosse } \\
\text { Wärme- } \\
\text { einheiten }\end{array}$ \\
\hline $\begin{array}{l}\text { Sauerstoff- } \\
\text { verbrauch } \\
\text { auf } 1 \text { Kilo- } \\
\text { oramm } \\
\text { Thier und } \\
\text { auf } 1 \text { Stun- } \\
\text { de in } \\
\text { Litern redu- } \\
\text { cirt auf } \\
0^{\circ} \mathrm{C} \text {. und } \\
\text { den Druck } \\
\text { von } 1 \mathrm{~m} \mathrm{Hg}\end{array}$ & 0,528 & 0,668 & 0,674 & 0,683 & 0,496 \\
\hline
\end{tabular}

erhält, als es wirklich braucht (Erhaltungsfutter), oder ob ihm viel weniger oder viel mehr geboten wird.

Es sind ja nun allerdings Unterschiede in der Höhe des Stoffwechsels vorhanden, welche darauf hindeuten, dass derselbe bei ge- 
ringer Fleischzufuhr etwas niedriger als bei Erhaltungsfutter und bei Erhaltungsfutter wieder etwas niedriger als bei Ueberfütterung. Die Unterschiede erscheinen aber, wie man sieht, so klein, dass sie nicht als vollkommen gesichert betrachtet werden dürfen.

Die grosse Bedeutung der mitgetheilten Thatsachen erhellt, wenn man in Betracht zieht, dass. derselbe Kater, weil er bald mehr, bald weniger, bald gar kein Fleisch erhielt, erhebliche Schwankungen seines Körpergewichtes zeigte.

\begin{tabular}{|c|c|c|}
\hline & 13. April & wog er 2500 \\
\hline & 23. Januar & $\Rightarrow 2600$ \\
\hline & 7. October & 3700 \\
\hline & 30. December & $\Rightarrow 4390$ \\
\hline
\end{tabular}

Es kann desshalb leicht unbeschadet der Gesundheit vorkommen, dass sich in kurzer Zeit das Gewicht eines Katers durch Zufuhr ausreichender Fleischmengen verdoppelt. Obigem Gesetz gemäss ist dann auch der Stoffwechsel auf das Doppelte gestiegen, weil das gefütterte Fleisch sich theilweise als "Fleisch", d. h. als Zellsubstanz, im Körper des Thieres abgelagert hat. Da nun. Zellsubstanz nur aufgebaut werden kann durch Zufuhr von Eiweiss, so ist es klar, dass das Maximum der Zellsubstanz in Körper nur aufgehäuft werden kann durch Ernährung mit dem Maximum von Eiweiss. Weil aber die Arbeitsfähigkeit abhängt von der Masse der Zellsubstanz, wie das für den Muskel längst feststeht, so ist es einleuchtend, dass die grösste Leistungsfähigkeit des lebendigen Körpers nur erzielt werden kann, wenn in der Nahrung die grösstmögliche Menge von Eiweiss zugeführt wird.

Der Eiweissgehalt der Nahrung steigert also den Stoffwechsel, weil und insofern er in erster Linie das Gewicht der Zellsubstanz vermehrt. Es ist eben mehr arbeitende Masse vorhanden. - Dả aber alles Eiweiss der Nahrung meiner Ansicht nach erst oxydirt wird, nachdem es Zellsubstanz geworden ist, stejgert alle Eiweissnahrung den Stoffwechsel, weil sie zunächst zur Vermehrung der Zellsubstanz beiträgt.

Die mitgetheilten Thatsachen über Fleischmästung lassen keinen Zweifel, dass im Allgemeinen die Katze mehr Fleisch $\mathrm{zu}$ verdauen vermag, als ihrem Bedürfniss entspricht. Dieser Satz gilt $\mathrm{nicht}$ allgemein, und wenn er gilt, in sehr verschiedenem Umfang, weil es ein Mästungsmaximum gibt, das wir z. B. in dieser Versuchsreihe erreichten. In diesem Falle zersetzt der Kater eben so 
viel Eiweiss als zugeführt wird, ohne dass bis jetzt entschieden werden kann, ob dies darum der Fall ist, weil das Thier nicht mehr verdauen kann und aus diesem Grunde eine grössere Zufuhr von Eiweiss verweigert. Es würden die Organe vielleicht noch mehr Eiweiss als Zellsubstanz ansetzen, wenn von den Verdauungswerkzeugen mehr Eiweiss zugeführt. werden könnte.

Die Gesetze, die ich hier für den Eiweissstoffwechsel der Katze dargelegt habe, sind von mir ${ }^{1}$ ) im Wesentlichen schon (1892) auf Grund von Untersuchungen am Hunde erkannt, so dass keinerlei Unterschied zwischen beiden Thierarten mit Rücksicht hierauf angenommen werden darf.

Es erscheint zur Sicherung der Ergebnisse von Wichtigkeit, die durch die Athemversuche gewonnenen Werthe mit den durch Wägung des Körpergewichts des Thieres erhaltenen zu vergleichen.

Beginnen wir mit der Ueberfütterung, so wäre aus dem Sauerstoffverbrauch die erzeugte Wärme zu berechnen und zu vergleichen mit derjenigen, welche durch die zugefübrte Nabrung gebildet worden ist.

Zu dem Ende ist uns die Kenntniss des Wärmewerthes (calorischen Coefficienten) des Sauerstoffs, der fettfreies Muskelfleisch im Organismus oxydirt, zu wissen nöthig.

Weil die Bestimmung des Werthes dureh Rubner Ungenauigkeiten enthält, muss ich ihn nochmals berechnen. Denn Rubner's Zahl für den Kohlenstoffgehalt des Fleisches ist zu hoch; auch hat er den Kohlenstoffgehalt des Kothes in Rechnung gestellt, ohne den Fettgehalt desselben $\mathrm{zu}$ berücksichtigen.

100 Gramm Trockenfleisch würden nach $R u b n$ er ${ }^{2}$ ) 2,7 Gramm Trockenkoth liefern mit folgender Zusammensetzung: enthaltend $26,5 \%$ Fett $\left.^{3}\right)=0,72$ Fett absolut

$$
\begin{array}{rcccc} 
& \mathrm{C} & \mathrm{H} & \mathrm{N} & \mathrm{O} \\
1,67 & 0,25 & 0,24 & 0,54 \\
0,72 \text { Fett darin }= & 0,55 & 0,09 & & 0,08 \\
\hline \text { fettfreier Koth } & 1,12 & 0,16 & 0,24 & 0,46
\end{array}
$$

1) E. Pflüger, Ueber Fleisch- und Fettmästung. Dieses Archiv Bd. 52 S. 75. 1892 .

2) Rubner, Zeitschr. f. Biologie Bd. 31 s. 319, 364.

3) E. Pflüger, Dieses Archiv Bd. 51 s. 30. 
100 Gramm Trockenfleisch liefern nach $\mathrm{Rubner}$ im Harn:

$$
\begin{array}{llll}
38,2 & = & 9,63 & 2,52 \\
\text { Abfall } & \frac{\left.15,25^{1}\right)}{10,75} & 2,68 & 10,90 \\
15,49 & 11,36
\end{array}
$$

100 Gramm Fleisch nach Stohmann ${ }^{2}$ ):

$$
\begin{aligned}
& \begin{array}{lrrrr} 
& 49,25 & 6,91 & 15,49 & 23,03 \\
\cline { 2 - 5 } \text { Differenz } & 38,50 & 4,23 & & 11,67
\end{array} \\
& \text { Sauerstoff nöthig für C } 38,5=102,70
\end{aligned}
$$

$$
\begin{aligned}
" \text { H } 4,23 & =\frac{33,84}{136,540} \\
\text { Summe } & =136 \\
\text { im Fleisch vorhanden } & =11,67 \\
\text { noch nöthig } & =124,87 \mathrm{O} .
\end{aligned}
$$

Da nun in 100 Gramm fettfreiem Trockenfleisch im Mittel nach Stohmann und Rubner 15,44\% $\mathrm{N}$ und nach meinen auf Grund dieser Zahl für den Procentgehalt an Stickstoff ausgeführten Bestimmungen $^{3}$ ) $1 \mathrm{~N}=20,76$ grosssen Wärmeeinheiten, so liefern die 100 Gramm Trockenfleisch 413,2 grosse Wärmeeinheiten, nachdem sie durch 124,87 Gramm Sauerstoff oxydirt worden sind. Der calorische Coefficient des Sauerstoffs ist also für Muskelfleisch

$$
3,3 .
$$

Rubner fand 3,0 ; mein Werth ist um $10 \%$ grösser.

Die älteren Bestimmungen des Wärmewerthes des Sauerstoffs bei der Verbrennung von Eiweiss durch Lilienfeld ${ }^{4}$ ) und Danilewsky ${ }^{5}$ ) sind zu einer Zeit angestellt, als die Verbrennungswärmen der bei der Berechnung in Betracht kommenden Substanzen noch nicht so genau bekannt waren, wie sie es jetzt durch das Verdienst von Stohmann und Rubner sind.

In einer aus dem thierphysiologischen Institut der landwirthschaftlichen Hochschule zu Berlin von Ad. Magnus-Lev ${ }^{6}$ ) herausgegebenen Arbeit wird im Jahre 1893 der Wärmewerth des Sauerstoffs bei Verbrennung von Muskelfleisch noch nach Rubner zu

1) Hier ist wegen Stohmann's Fleischanalyse die unwesentliche Aenderung: statt 15,16 habe ich 15,25 geschrieben.

2) Stohmann und Langbein, Journ. f. prakt. Chemie, N.-F., Bd. 44 S. 364 (1891).

3) E. Pflüger, Dieses Archiv Bd. 52 S. 78.

4) Lilienfeld, Dieses Archiv Bd. 32 S. 340.

5) Danilewsky, Dieses Archiv Bd. 36 S. 248.

6) Magnus-Levy, Dieses Archiv Bd. 55 S. 7 (1893): 
3,00 gesetzt, obwohl ich schon $1892^{1}$ ) die falschen Zahlen, auf denen die Berechung Rubner's ruht, verbessert hatte.

Bei grösster Fleischzufubr verbrauchte nun 1 Kilo Katze in der Stunde 0,683 Liter $0\left(0^{\circ}\right.$ C. und $\left.1 \mathrm{~m} \mathrm{Hg}\right)=1,285$ Gramm 0 .

Das Thier von 3,329 Kilo verbrauchte also in 24 Stunden 102,67 Gramm $O=338,8$ grosse Wärmeeinheiten.

In der Nahrung wurden täglich zugeführt 439 grosse Wärmeeinheiten. Weil das Fleisch in grösstmöglichem Ueberschuss gefüttert wurde, lebte das Thier nur von Eiweiss.

Nach früher angegebenen Analysen lieferten 100 Gramm des gefütterten Fleisches im Ganzen 110,349 grosse Wärmeeinheiten, zu denen das Eiweiss 85,77 beisteuerte. Also machte die durch das Eiweiss hervorgebrachte Wärme 77,7\% der Gesammtwärme aus.

Die Gesammtwärme war 439. Folglich würde die Oxydation des gesammten Eiweiss der Nahrung hervorbringen

341,1 grosse Wärmeeinheiten.

Aus Sauerstoffiverbrauch haben wir berechnet:

338,8 .

Diese Uebereinstimmung ist ausserordentlich. Sie beweist, dass bei üppigster Fleischfütterung alsbald ein Zustand des lebendigen Körpers in Folge der Fleischmästung eintritt, bei dem alles anfgenommene Eiweiss oxydirt wird, so zwar, dass der ganze Stoffwechsel nur durch Eiweiss sich vollzieht.

Ehe wir zur Beurtheilung der Versuche mit Erhaltungsfutter u.s. w. übergehen, wird der calorische Coefficient des Sauerstoffs für Fette und Stärke nochmals zu prüfen und zu berechnen sein, nachdem sich herausgestellt hat, dass $\mathrm{Rubner}$ 's Zahl für die Verwerthung des Muskelfleisches nicht richtig war.

Da 100 Gramm thierisches Fett 288,5 Gramm Sauerstoff zur vollkommenen Oxydation bedürfen, und da nach Stohmann ${ }^{2}$ ) 1 Gramm dieses Fettes bei der Verbrennung 9,5 grosse Wärmeeinheiten erzeugt, ergibt sich als calorischer Coefficient für den Sauerstoff

$$
3,29 \text {, }
$$

Rubner's Zahl ist 3,27 und weicht von der meinigen also nur sehr wenig ab.

1) E. Pflüger, Dieses Archiv Bd. 52 S. 1 ff.

2) Stohmann-Langbein, Journ. f. prakt. Chemie (2) Bd. 42 S. 361 (1890). 
100 Gramm Stärke verlangen zur vollkommenen Oxydation 118,54 Gramm Sauerstoff und erzeugen hierbei nach Stohmann 419,12 grosse Wärmeeinheiten. 1 Gramm Sauerstoff entwickelt also 3,54 grosse Wärmeeinheiten. Da aber nach Rubner und mir die Stärke nur einen Nutzwerth von $96 \%$ hat, ergibt sich als calorischer Coefficient des Sauerstoffs für Stärke:

\section{3,4 grosse Wärmeeinheiten.}

Wir stellen diese hochwichtigen Werthe des calorischen Coefficienten in folgendem Täfelchen übersichtlich zusammen:

Tabelle XV.

\begin{tabular}{c|c|c|c|c}
\hline Substanz & $\begin{array}{c}100 \text { Gramm } \\
\text { brauchen zur } \\
\text { vollkommenen } \\
\text { Oxydation im } \\
\text { Organismus } \\
\text { Sauerstoff in } \\
\text { Gramm }\end{array}$ & $\begin{array}{c}100 \text { Gramm } \\
\text { liefern grosse } \\
\text { Wärme- } \\
\text { einheiten bei } \\
\text { der Oxydation }\end{array}$ & $\begin{array}{c}1 \text { Gramm } \\
\text { Sauerstoff lie- } \\
\text { fert grosse } \\
\text { Wärme- } \\
\text { einheiten } \\
\text { Calorischer } \\
\text { Coefficient) }\end{array}$ & $\begin{array}{c}\text { Der calorische } \\
\text { Werth des? } \\
\text { Sauerstoffs für } \\
\text { Fleisch wird } \\
=100 \text { gesetzt }\end{array}$ \\
\hline $\begin{array}{c}\text { Fettfreies } \\
\text { trockenes } \\
\text { Muskelfleisch }\end{array}$ & 124,87 & 414,5 & 3,32 & 100,0 \\
Fett & 288,50 & 950,0 & 3,29 & 99,1 \\
Stärke & 118,54 & 419,12 & 3,40 & 102,4
\end{tabular}

Es mag nicht unerwähnt bleiben, dass der lebendige Körper in den Ausgaben ein wenig Fett durch den Koth und die Hautabsonderungen verliert. Da dieser Fettverlust unabhängig von der Menge des gefütterten Fettes ist, so bleibt bei sehr genauen Untersuchungen nur übrig, die Ausgabe durch Fett bes onders in der Bilanz in Rechnung zu stellen. Jedenfalls ist also auch für das Fett der Nutzwerth nicht ganz $=100 \%$.

Es ergibt sich aus der gegebenen Uebersicht, dass der calorische Coefficient des Sauerstoffs immer nahezu denselben Wert hat, gleichgültig, ob es sich um die Oxydation von Eiweiss, Fett oder Stärke handelt. Diese ausserordentlich wichtige Thatsache liefert uns zur Messung der Grösse des Stoffwechsels eine sichere Handhabe.

Wenden wir uns nun zu der Betrachtung des Stoffwechsels bei Erhaltungsfutter.

1) Brief Stohmann's an.Pflüger, Dieses Archiv Bd. 52 S. 78 (1892). 
Die Wägung des Thieres und die Analyse der Nahrung hat, wie ich bereits mitgetheilt habe, den Werth des Stoffwechsels ergeben $\mathrm{zu}$ :

\section{7,1 grossen Wärmeeinheiten.}

Der Athemverbrauch lieferte nun folgendes Ergebniss:

Gebraucht hatte das Thier auf 1 Kilo und 1 Stunde 0,674 Liter Sauerstoff $\left(0^{0} \mathrm{C}\right.$ und $\left.1 \mathrm{~m} \mathrm{Hg}\right)=1,2685$ Gramm.

Da das Thiergewicht 3,530 Kilo, so beträgt der Verbrauch in 24 Stunden:

107,46 Gramm Sauerstoff

entsprechend 354,62 grossen Wärmeeinheiten.

Weil die durch Athmung gewonnene Zahl sich auf ein Körpergewicht des Katers von 3,580 Kilo, die durch Wägung ermittelte auf ein solches von 3,439 Kilo bezieht, ermässigt sich der Werth von 354,62 auf

\section{$345 \check{5}, \mathfrak{0}$ grosse Wärmeeinheiten.}

Es ist immerhin eine Abweichung der beiden Werthe von $5,3 \%$.

Bedenkt man überdies; dass der Sauerstoffverbrauch eines Thieres bei Einnahme von Erhaltungsfutter zu einer bestimmten Stunde auf- und abschwankt, kann man nicht verlangen, dass zwei beliebig herausgegriffene Stunden den wahren Mittelwerth geben.

Also durch Wägung des Körpergewichts gefunden 327,1 grosse Wärmeeinheiten.

Durch Bestimmung des Sauerstoffs

345,5 grosse Wärmeeinheiten.

Die mitgeteilten Versuche haben den Beweis geliefert, dass man ohne Athenversuche durch Wägung des Körpergewichtes, wenn man Menge und Zusammensetzung der Nahrung kennt, das Nahrungsbedürfniss annähernd bei Katzen bestimmen kann. - Ich habe dasselbe auch schon für den Hund gezeigt. - Ich gebe allerdings zu, dass die grösste Vorsicht und mehrere Wochen andauernde Versuchsreihen notwendig erscheinen.

Wenden wir uns zu den Versuchen mit ungenügender Fleischnahrung, so ergab sich auf 1 Kilo Thier und 1 Stunde 0,668 Liter Sauerstoff $=1,2572$ Gramm.

1) E. Pflüger, Dieses Archiv Bd. 52 S. 1 u. s. w. 
Also für 24 Stunden und 2,637 Kilo Thier

79,566 Gramm Sauerstoff $=262,57$ grosse Wärmeeinheiten.

In der Nahrung wurflen dem Thiere zugeführt nur 199 grosse Wärmeeinheiten. Es fehlten 63,57, welche der Organismus so reichlich lieferte, dass der Stoffwechsel fast ganz die normale Höhe behauptete.

Gehen wir endlich zu den Hungerversuchen über, so ist ein bedeutendes Sinken der Oxydationsprocesse vorhanden. Denn auf 1 Kilo Thier entfallen nur

$$
\text { 0,528 Liter Sauerstoff }=0,9937 \text { Gramm. }
$$

Macht für 24 Stunden und das Thier von 2,825 Kilo

67,352 Gramm Sauerstoff $=222,33$ grosse Wärmeeinheiten.

Das Sinken des Stoffwechsels im Hunger ist kein Schein, der etwa dadurch hervorgebracht wäre, dass das Thier fast nur auf Kosten seines Körperfettes lebt. Denn ich habe bewiesen, dass der calorische Coefficient für Eiweiss und Fett denselben Werth hat.

Nachdem wir die der Katze zukommende Kraft des Stoffwechsels bestimmt haben, wird es zweckmässig sein, dieselbe mit der des Hundes $\mathrm{zu}$ vergleichen.

Nach den Untersuchungen Regnaults ${ }^{1}$ ) an mit rohem Fleisch gefütterten Hunden schwankt der Sanerstoffverbrauch, auf 1 Kilo und 1 Stunde bezogen, bei einem Körpergewicht von 4757 bis 6393 Gramm von

\section{1,016 Gramm bis 1,393 Gramm.}

Auf Grund unserer Untersuchung schwankt der Sauerstoffverbrauch der mit Fleisch gefütterten Katze, auf 1 Kilo und 1 Stunde bezogen, bei einem Körpergewicht von 2637 bis 4390 Gramm von 1,257 bis 1,285 Gramm.

Da sicher individuelle Schwankungen im Stoffwechsel vorkommen und die Zahl der untersuchten Thiere nicht gross ist, so kann diese Vergleichung nur als eine Annäherung betrachtet werden. Sie genügt zu zeigen, dass in der Intensität des Stoffwechsels kein wesentlicher Unterschied zwischen Hund und Katze besteht.

Nachdem der Einfluss, welchen die Vergrösserung der Eiweisszufuhr auf die Grösse des Stoffwechsels ausübt, aufgeklärt ist, wollen wir noch die Frage behandeln, ob die Katze in der That so un-

1) Regnault et Reiset, Ann. d. Chim. et de phys. (3) t. 26 (1849). 
geheure Eiweissmengen zu verdauen vermöge, dass sie das Nahrungsbedürfniss um ein Mehrfaches übertreffen.

Die Frage muss in erster Linie den Ernährungszustand des Thieres in das Auge fassen.

Werfen wir einen Blick auf Tab. VII, so erkennen wir, dass der Kater, nachdem er durch ${ }_{n}$ reichliche Eiweisszufuhr ein sehr hohes Gewicht bis 4390 Gramm in der Zeit vom 17. bis 30. Dec. 1898 erreicht hatte, nicht mehr Eiweiss verdauen konnte, als durch den Stoffwechsel zerstört wurde.

Der Kater war im Stancle, mehr Eiweiss zu verdauen, als das Bedürfniss verlangte, während er noch ein geringeres Körpergewicht besass.

Denn er nahm dann durch 'reichliche Fleischfütterung an Gewicht $\mathrm{zu}$, weil sich Fleisch in seinem Körper ablagerte.

Die Tabelle VII lehrt, dass das Gewicht des Katers von 3530 bis 4390 Gramm, d. h. um $860 \mathrm{Gramm}=24,1 \%$ zugenommen hat - und zwar in 13 Tagen (vom 17. bis 30. Dec. 1898).

Gefressen hat das Thier im Ganzen 6170 Gramm Fleisch. Nach meiner bereits mitgetheilten Untersuchung hat eine Katze, der dauernd Fleisch in Ueberfülle zur Verfügung steht, stets Fleisch in dem Magen, der ungefähr 200 Gramm aufnehmen kann. Die Gewichtszunahme des Körpers der Katze ist also sicher kleiner, als es nach obiger Rechnung scheint. Da es sich aber hier darum handelt, zu zeigen, dass die Katze keineswegs ein so bohes Vermögen für Fiweissverdauung besitzt, will ich keine Correctur an der in 13 Tagen aufgenommenen Fleischmenge anbringen, sondern annehmen, dass das Fleisch ganz verdaut worden sei.

Es folgt aber mit Nothwendigkeit, dass die Eiweissmenge, welche der Kater mehr, als dem Bedarf gemäss ist, verdauen kann, um so grösser ist, je mehr der Ernährungszustand des Thieres heruntergekommen ist. Um das relative Maximum der Verdauung des Fleisches zu erfahren,' müssen wir demnach die ersten Tage der Fleischmästungsperiode in Betracht ziehen.

Nimmt man zur Ausgleichung der täglichen Unregelmässigkeiten immer 3 Tage, so ergibt sich (laut Tabelle VII): 
Tabelle XVI.

\begin{tabular}{|c|c|c|}
\hline $\begin{array}{c}\text { Datum } \\
1898 \\
\text { December } \\
\text { vom }\end{array}$ & $\begin{array}{l}\text { Gewichtszunahme } \\
\text { des Katers in } \\
3 \text { Tagen in Gramm }\end{array}$ & $\begin{array}{l}\text { Gewichtszunahme } \\
\text { des Katers in } \\
1 \text { Tag in Gramm }\end{array}$ \\
\hline $17-20$ & 3530 bis 4020 & 163 \\
\hline $20-23$ & 4020 & 60 \\
\hline $23-26$ & $4200 " \quad 4330$ & 43 \\
\hline $26-29$ & $4330 " \quad 4380$ & 17 \\
\hline
\end{tabular}

Die Mästung vom 17. bis 20. December entspricht annähernd 179,9 grossen Wärmeeinheiten, während das Thier, als es noch ein wenig leichter war, ein Bedürfniss von 327,1 grossen Wärmeeinheiten besass.

Die Sache liegt aber nicht so günstig, als es hiernach scheint.

Wenn die Katze bei 3439 Gramm Gewicht ein Bedürfniss von 327,1 grossen Wärmeeinheiten hat, und wenn sie nur von Eiweiss leben soll, so muss sie 381,4 Gramm Fleisch in 24 Stunden verdauen, weil $100 \mathrm{Gramm}$ dieses Pferdefleisches 85,77 Wärmeeinheiten liefern, die durch Oxydation des Fiweisses entstehen. Das Maximum, was die Katze verdauen konnte, waren (laut Tabelle VII) etwa 500 Gramm Fleisch. Wenn die Katze sich nur durch Eiweiss ernähren soll und der Ernährungszustand des Thieres vorausgesetzt wird, der bei Erhaltungsfutter vorhanden war, kann durch die Vermehrung der Eiweisszufuhr nur etwa $31.1 \%$ mehr Eiweiss verdaut werden.

Weil der durch die Eiweissverdauung gelieferte, das Bedürfniss überschreitende Uebersehuss, wie ich oben darlegte, um so bedeutender ist, je herabgekommener der Ernährungszustand des Katers, so muss der eben berechnete Werth mehr und mehr wachsen, je leichter das Thier durch Entbehrung geworden ist. Denn die Kraft der Eiweissverdauung eines Thieres nimmt viel langsaner als das Körpergewicht ab. Erst wenn das mathematische Gesetz der beiden Beziehungen genauer bekannt ist, lässt sich bestimmen, um wie viel die Zahl von $31.1 \%$ noch unter Umständen wachsen kann.

Wenn man es mit den Folgen länger andauernder Ueberfütterung mit Fleisch zu thun hat, wird dieser Punkt weniger in Betracht kommen.

Nachdem der Einfluss, den eine Vermehrung der Fleischnahrung auf den Stoffwechsel ausübt, aufgeklärt ist, muss ich noch einmal 
auf die 2 Versuchsreihen zurückkommell, durch welche Bidder und Schmidt eine so grosse Verwirrung veranlasst haben.

Nach genauer Prüfung aller Zahlen und Rechnungen der Bilanzen ergibt sich ein merkwürdiges Naturgesetz, das nach meiner hier dargelegten Untersuchung nicht existirt. Nach Bidder und Schmidt wächst der Stoffwechsel sofort auf das Doppelte, wenn das Erhaltungsfutter, das aus Fleisch besteht, verdoppelt wird. Zur Erklärung des Räthsels dachte ich zuerst an Beobachtungsfehler, die ich nicht finden konnte. Ich gab dies Suchen auf, als ich die genaue Uebereinstimmung aller Werthe in Einnahme und Ausgabe sah und doch wusste, dass sie unmöglich ist. Um nur Eines hervorzuheben: Beim Erhaltungsfutter, das reich an Fett war, erscheint natürlich der eingeführte Kohlenstoff und Stickstoff wieder in den Ausgaben.

Die 142,41 Gramm Fleisch (Erhaltungsfutter) enthielten laut Analyse 6,75 Gramm Fett $=64,1$ Wärmeeinheiten und 4,49 Gramm N.

Als nun die Nahrung auf 247,32 Gramm Fleisch gesteigert wurde, mussten die 64,1 Wärmeeinheiten, die bisher durch Fett geliefert wurden, nun durch Eiweiss bestritten werden. Es musste desshalb die Stickstoffausscheidung um 2,4 Gramm wachsen. 4,49+ 2,4 Gramm $\mathrm{N}=6,89$ Gramm $\mathrm{N}$. In der Bilanz steht aber 7,79 Gramm $\mathrm{N}$ als Gesammtausscheidung, also 0,9 Gramm $\mathrm{N}$ zu viel. Warum zu viel? Nun, in dem gefütterten Fleisch hefanden sich eben 7,79 Gramm N.

Viel lehrreicher ist noch die Bilanz des Kohlenstoffs: Das mit Fleisch überfütterte Thier lebt von Eiweiss, also kann in den Ausscheidungen nur so viel Kohlenstoff erscheinen, als dem ausgeschiedenen Stickstoff entspricht. Man findet diesen Kohlenstoff, wenn man den ausgeschiedenen Stickstoffwerth mit 3,2 multiplicirt. Da ergibt sich denn 24,93 Kohlenstoff. Bei Bidder und Schmidt steht aber 34,80 für den Kohlenstoff, der also um $39,6 \%$ zu hoch angegeben ist.

Wenn man nun fragt, wie kommt denn die grosse Zahl für den Kohlenstoff in die Bilanz, so ist die Antwort sehr einfach. Im gefütterten Fleisch ist so viel Kohlenstoff auf 7,79 Stickstoff vorhanden. Auf S. 337 sagen Bidder und Schmidt geradezu, dass diese "theoretische" Zahl in den Ausscheidungen herauskommen müsse, was ja ganz falsch ist. Denn mit dem $\mathrm{N}$ braucht in den Aus- 
scheidungen nur $\mathrm{C}$ aus Eiweiss zu erscheinen, nicht aber nothwendig auch $\mathrm{C}$ aus Fett. Nun führen sie zwei Bestimmungen der in 1 Stunde ausgeathmeten Kohlensäure an, die zwar zu gross, aber kleiner als der von ihnen berechnete Werth sind. Diese zu kleinen Werthe werden dann abgerundet, d. h. bis zur gewünschten Höhe willkürlich vergrössert. - Mehr zu sagen ist überflüssig.

Auf der Grundlage des bisher Erörterten bin ich nun im Stande, eine befriedigende Erklärung von der sogenannten „Luxus-Consumption" des Eiweiss zu geben. Vorerst ist hervorzuheben, dass im Allgemeinen auch bei den Fleischfressern der Stoffwechsel durch die Oxydation von Eiweiss, Fett und Kohlehydraten unterhalten wird. Denn auch das Fleisch, welches der reine Fleischfresser verzehrt, enthält neben Eiweiss oft sehr grosse Mengen von Fett neben geringen von Kohlehydraten. Das hungernde Thier lebt auf Kosten seines eigenen Körpers, der Fett neben kleinen Mengen von Eiweiss und Kohlehydrat beisteuert.

Nun ist es gewiss, dass ein Thier gerade so viel Nahrung oxydirt, als seinem Bedürfniss entspricht. Das Thier gebraucht mit einem Worte zur Bestreitung seiner Lebensleistung eine bestimmte Menge von Arbeitskraft, deren Grösse wir durch Wärmeeinheiten ausdrücken.

Man weiss ferner, dass der lebendige Organismus die Nährstoffe nicht in gleicher Weise verwerthet. Er bevorzugt das Eiweiss und befriedigt seine Bedürfnisse in erster Linie durch dieses und benutzt Fett und Kohlehydrat erst dann, wenn es an Eiweiss fehlt. -

Wenn man also einem in gewöhnlicher Weise ernährten oder hungernden Thiere eine Zulage von Eiweiss in der Nahrung gewährt, so macht der Lebensprocess sofort hiervon Gebrauch und zersetzt es. Um dies aber richtig aufzufassen, muss man im Auge behalten, dass für das so zersetzte Eiweiss eine gleichwerthige Menge von Fett und Koblebydrat weniger oxydirt, also gespart wird. Das ist kein Luxus, weil der Körper des lebendigen Thieres genau so viel Arbeitskraft benutzt, als ob er die Eiweisszulage nicht erhalten hätte. Der Grund der Bevorzugung des Eiweiss im Stoffwechsel, welcher die Ursache der Lebensleistungen ist, liegt wohl darin, dass das Eiweiss das geeignetere Material darstellt.

Es tritt nun durch eine Zulage von Eiweiss zu dem Erhaltungsfutter auch dann eine Steigerung der Eiweisszersetzung ein, wenn das Erhaltungsfutter bereits nur aus Eiweiss besteht, sodass voll einer Vertretung von Fett oder Kohlehydrat keine Rede mehr sein kann. 
Diese Art der Eiweisszufuhr ezengt stets eine Zunahme des Gewichtes des Thieres durch Ablagerung von Eiweiss als Zellsubstanz. Weil nun die Höhe des Stoffwechsels und das Bedürfniss wachsen muss mit der Masse der lebendigen Zellsubstanz, muss auch bei Vermehrung der Eiweisszufuhr die Eiweisszersetzung wachsen. Wir wissen, dass die Arbeitskraft eines Muskels um so grösser ist, je schwerer oder voluminöser er erscheint. Un die Muskeln eines Thieres auf das doppelte Gewicht zu bringen, gibt es kein anderes Mittel als äusserst vermehrte Fiweisszufuhr. Weil der vergrösserte Muskel täglich eine seiner Zunahme entsprechende vergrösserte Arbeit leistet - (ich denke hier zunächst an die chemische Arbeit der O-Absorption u. s. w.) - , muss zu seiner Erhaltung mehr Eiweiss zugeführt werden, wenn Eiweiss allein die Nahrung bildet. - Die mit dem Wachsthum des Muskels verbundene vermehrte Zersetzung des Eiweiss ist kein Luxus; denn sie ist nur der Ausdruck für die gesteigerte Leistung und Arbeitsfähigkeit. Di es g e $\mathrm{n} \ddot{\mathrm{g}} \mathrm{t}, \mathrm{zu}$ ze igen, dass es keine Luxusconsumption gibt. - Was geschieht, ist zweckmässig und mehrt die Sicherheit des Lebens der Thiere.

Die wichtige Schlussfolgerung aus obiger Darlegung besteht darin, dass nur die reichlichste Eiweisszufuhr den lebendigen Körper in den Zustand der höchsten Leistungsfähigkeit bringt. Es fragt sich nun, durch welche Ernährung die hohe Arbeitskraft des Organismus erhalten werden kann, vor Allem, welche Bedeutung hierbei dem Eiweiss zufällt, da nach verbreiteten heutigen Ansichten es ziemlich gleichgültig ist, ob in der Nahrung viel oder wenig Eiweiss enthalten sei. -

Wenn man bei einem Thiere, wie ich es gethan und beschrieben habe, durch reichlichste Zufuhr von Eiweiss die höchste Arbeitskraft herangezüchtet hat, weil gerade so viel Eiweiss zersetzt als zugeführt wird, so lässt sich der Zustand des Thieres nur erhalten, wenn die gefütterte Eiweissmenge nicht um eine Spur verringert wird, selbst wenn man die Verminderung der Eiweisszufuhr ausgleicht durch Zufuhr einer Menge von Fett + Kohlehydrat von gleichem, ja grösserem Wirkungswerthe. Führt man diesen Versuch aus, so weiss man ja, dass sich im Laufe einiger Tage wieder Stickstoffgleichgewicht herstellt, dadurch, dass eine Zeitlang das Thier mehr Eiweiss zersetzt als aufnimmt. Je näher also der Körper dem Maximum der Leistungsfähigkeit ist, um so weniger kann Eiweiss der Nahrung durch stick- 
stofffreie Substanz vertreten werden, ohne dass die Arbeitskraft herabgesetzt wird.

Sobald man bei einem in Stoffwechsel- und Stickstoffgleichgewicht befindlichen Thiere, das mit gemischter Nahrung erhalten wird, einen Theil des bisher gereichten Eiweiss durch eine isodyname Menge von Fett oder Kohlehydrat ersetzt, so wird in der nächsten Zeit das Stickstoffgleichgewicht aufgehoben und eine Zeit lang mehr Stickstoff ausgeschieden als aufgenommen. Folglich verliert der Organismus, welcher das Erbaltungsfutter in gemischter Nahrung erhält, stets an Leistungsfähigkeit, wenn ein Theil der bisher gereichten Eiweissmenge durch stickstofffreie Nahrung ersetzt wird. Weil dieser Satz allgemein giit, mag ein Thier reicher oder weniger reich an Zellsubstanz sein, so folgt mit mathemathischer Nothwendigkeit, dass die Leistungsfähigkeit eines Organismus um so mehr berabgesetzt wird, je mehr Eiweiss bei gemischter Nahrung durch Fett und Kohlehydrat ersetzt wird. Es bedarf einer Untersuchung, um zu ermitteln, um wie viel sich der Organismus von dem Maximum der Leistungsfähigkeit entfernt, wenn die maximale Futtermenge des Eiweiss um einen bestimmten Betrag vermindert wirh.

Diese Darlegungen zeigen, dass die von mir "unersetzliche" Eiweissmenge der Nahrung genannte Grösse einen veränderlichen von dem Ernährungszustande abhängigen Werth darstellt.

Einige Bemerkungen über die starke Erniedrigung des Stoffwechsels, welche durch die Entziehung der Nahrung erzeugt wird. Während des Hungerns tritt eine Aenderung des Stoffwechsels ein, welche um so bedeutender erscheint, je reicher das Thier vorher mit Eiweiss ernährt worden ist. Diese Aenderung dauert eine Reihe von Tagen und bestebt darin, dass die Bedürnisse immer mehr durch Fett und immer weniger durch Eiweiss befriedigt werden. Diese Aenderung kann nicht anders gedeutet werden, als eine Einrichtung zur möglichsten Sicherung des Lebens. Der Verbrauch von Eiweiss heisst hier Zerstörung von Zellsubstanz, Herabsetzung der Arbeitskraft. Folglich wird das hungernde Thier am längsten arbeitsfähig bleiben, wenn es so wenig als möglich von seinem Eiweiss lebt. Demnach muss das Fett zur Bestreitung der Bedürfnisse in verstärktem Maasse herangezogen werden. Dadurch geschieht der Arbeitskraft des Thieres kein unmittelbarer Abbruch, der die Existenz bedroht. -

Die Aenderung des Stoffwechsels im Hunger gehört desshalb E. Pflügor, Archiv für Physiologie. Bd. 77. 
unzweifelhaft $\mathrm{zu}$ den durch den Kampf um das Dasein erworbenen Einrichtungen, die die Abwehr von Gefahren und Schädlichkeiten bedingen.

Wie Dr. N. Schulz auf meine Veranlassung in meinem Laboratorium gezeigt hat, wird während des Hungerns das Blut reicher an Fett als unter gewöhnlichen Verhältnissen, obwohl alle anderen Organe an Fett verarmen. Die Zellen brauchen eben jetzt mehr Fett als sonst. Es sind offenbar Stoffe entstanden, welche mebr Fett lösen, um es von seinen Stapelplätzen dem Blute zuzuführen.

Ich kann nicht umbin, das schnelle Schwinden des Glykogenes in der Leber in ähnlicher Weise zu deuten, wie ich es für das Fett gethan habe.

Fragt man sich, wie die Mechanik dieser Anpassung des Stoffwechsels an die Noth zu erklären sei, so kann der Schlüssel des Räthsels nur in der von mir begründeten Selbststeuerung gesucht werden. Das Bedürfniss veranlasst selbst - diesem Naturgesetz gemäss - die B efriedigung. Während des Hungerns fährt die Zellsubstanz fort, sich zu zersetzen, ohne dass eine genügende Neubildung der zersetzten Stoffe möglich ist. Dadurch entfernt sich die Zelle mehr und mehr von dem normalen Zustand. Da alle Zellen des lebendigen Körpers in gleicher Weise leiden, könnte, wie bei der Befriedigung des Athembedürfnisses, eine einzelne Gruppe von Zellen die für die Hungersnoth nothwendige Aenderung des Stoffwechsels veranlassen. Wenn man aber bedenkt, dass alle Zellen in gleicher Weise leiden, also sowohl diejenigen, welche unter der Herrschaft des Nervensystems stehen wie diejenigen, bei denen das nicht der Fall ist, und dass in allen die Oxydation herabgesetzt werden soll, so scheint es am zweckmässigsten, wenn jede Zelle sich selbst hilft. Das kann nur dadurch geschehen, dass sie mit wachsender Verarmung den Sauerstoff weniger stark anzieht, so zwar aber, dass die Verringerung des Sauerstoffverbrauchs der Zelle schneller wächst als die Verringerung des Zellgewichts. - Welche chemische Aenderung in der Constitution der Zellsubstanz hierbei eintritt, lässt sich nicht angeben. Dass aber die Gewichtseinheit der ausgehungerten Zelle weniger leicht oxydirbar geworden ist, kann man sich wohl denken. Da nach dem Gesetz der Selbststeuerung die ausgehungerten Zellen die ganze nothwendige Abhülfe schaffen, ist es wahrscheinlich, dass sie Stoffe in das Blut absondern, welche lösend auf Fett wirken, vielleicht auch Fermente, um das Glykogen der Leber in Zucker zu. 
verwandeln, der den Organen dann zur Verfügung in der Blutbahn gestellt werden kann.

Sicher ist die Senkung des Stoffwechsels im nüchternen Zustande auch noch durch den Wegfall der Verdaungsarbeit bestimmt, worauf N. Zuntz zuerst aufmerksam gemacht hat. Man weiss, dass die Speicheldrüse sich während der Secretion erhitzt, was beweist, dass stärkere Oxydationen durch die Arbeit des Organes bedingt sind.

Da nun alle Drüsen der Verdauungswerkzeuge erst zu arbeiten beginnen, sobald Speisen in den Magen eingeführt werden, kann man nicht zweifeln, dass die Verdauung eine Steigerung des Stoffwechsels bedingen muss. Selbst die Leber, welche auch im nüchternen Zustande absondert, steigert ihre Arbeit während der Verdauung. Auch die peristaltischen Bewegungen des Magens und der Gedärme, welche während der Verdauung lebhafter als im nüchternen Zustande erscheinen, müssen eine, wenn auch geringe Steigerung der Oxydationen zur Folge haben. Bei der Speichelsecretion der Mundhöhle sehen wir, dass sie auf reflectorischem Wege von den Schleimhautnerven veranlasst wird, sei es, dass diese chemisch oder mechanisch oder auch auf andere Weise gereizt werden. Man wird desshalb annehmen dürfen, dass das Gleiche für die Thätigkeit der in der Unterleibshöhle gelegenen Verdauungsdrüsen gelte.

Weil die Verdaung des in den Magen gelangten Eiweiss sofort beginnt, so werden sehr bald die ersten von der Nahrung stammenden resorbirten Eiweissstoffe von den Zellen der Organe angezogen werden und deren Oxydation steigern.

Vor der Hand genügen diese Erklärungen, um den Unterschied der Höhe des Stoffwechsels zu verstehen, der im Zustande der Verdauung und Nüchternheit beobachtet wird.

Dass bei sehr kleinen Thieren dieser Untersehied fast verschwindet, liegt wohl daran, dass diese wegen des verhältnissmässig sehr grossen Wärmeverlustes in ihrer Existenz bedroht sind, wenn die Regulation der Körpertemperatur sich nicht in der vollkommensten Weise vollzieht.

Es bleiben mir endlich noeh einige Bemerkungen über die Bedeutung der Fette und Kohlehydrate.

Es hat sich die auffallende Thatsache ergeben, dass der niedrig stehende Stoffwechsel der hungernden Katze bei Fütterung mit Fett und Kohlehydraten nicht zunimmt. Es ist sogar eine geringe $A b$ nahme eingetreten. Dass Fettzufuhr keine Steigerung des Stoff- 
wechsels bedingt, wird ziemlich allgemein zugegeben, während einige Forscher auch den Kohlehydraten wie dem Eiweiss eine Erregung des Stoffwechsels zuerkennen. Ich habe bereits in meiner Arbeit über Fleisch- und Fettmästung (1892) beim Hunde den Schluss ziehen müssen - auf Grund ganz anderer Methoden der Untersuchung, als sie hier benutzt wurden -, dass die Kohlehydrate keine Steigerung des Stoffwechsels erzengen. Es wird also weiterer Forschung bedürfen, um festzustellen, unter welchen Umständen Kohlehydrate den Stoffwechsel zu erregen vermögen. Mir scheinen hier wesentlich drei Bedingungen in das Auge gefasst werden zu müssen:

1. Es ist zuerst denkbar, dass gewisse Nahrungsstoffe durch ihre chemischen oder physikalischen Eigenschaften die Nerven der Schleimhaut in dem Magen und Darme reizen. Diese Reizung kann dann unter Vermittlung des centralen Nervensystemes reflectorisch auf die Muskeln u. s. w. wirken und - wie bei dem Einfluss der Kälte von der äusseren Haut her - die Oxydationsprocesse steigern. Eine derartige Beeinflussung würde also nicht durch die eigentliche Natur der Koblehydrate, sondern durch eine nicht wesentliche, zufällige Beschaffenheit derselben bedingt sein. Hierher wäre auch eine Ueberfüllung des Magens mit Kohlehydraten zu rechnen, die nur durch ihr Volum und Gewicht wirken.

2. Man könnte annehmen, dass die Kohlehydrate eine viel stärkere Anregung der Verdau ungsarbeit bedingten als die Fette, obwohl schwer zu begreifen ist, warum zarter, dünner Stärkeschleim oder Reisbrei mehr reizen soll als Fett.

3. Es ist denkbar, dass die Kohlehydrate nach ihrer Resorption und Uebergang in Zucker einen Reiz für die Zellenarbeit darstellen.

Dem Allem gegenüber muss ich nun darauf hinweisen, dass ich nicht die Spur einer erregenden Wirkung der Kohlehydrate bei der Katze gefunden habe. -

Die Herabsetzung des Stoffwechsels, welche die Zufuhr der Kohlehydrate bei der Katze bervorbrachte, erklärt sich vielleicht so: Ein hungerndes Thier ist unbehaglich und desshalb oft unruhig. Sobald der Kater aber etwas Nahrung im Magen hat - und wäre es auch den $\mathrm{ihm}$ verhassten Reisbrei -, fühlt er sich weniger gequält und wird ruhiger. - 
Einen wichtigen Punkt muss ich endlich noch erörtern. Sowohl bei Hunden als bei Katzen stösst man auf Schwierigkeiten, wenn sie stickstofffreie Nahrung verzehren sollen. Der Hund frisst wenigstens Butter und auch andere Fette oft gern in grosser Menge, ohne dass seine Gesundheit darunter leidet. - Eine Katze rührt das beste Fett nicht an, wenn sje nicht durch den heftigsten Hunger dazu gezwungen wird. Hat sie sich überwunden, so bricht sie alsbald das Fett wieder aus und zeigt ein mehrere Tage anhaltendes Unwohlsein. Den besten Reisbrei, der mit etwas Butter geschmelzt ist und den jeder Menscb gern essen würde, verschmäht die Katze oder frisst nur bei grossem Hunger eine kleine Menge.

Meine Absicht war es nun, der Katze Kohlehydrate in einer Form beizubringen, welche möglichst jede Reizung der Magennerven ausschloss. Da ich mit Stärkemehl nicht zum Ziele kam, wählte ich Reis, obwohl er ja nicht ganz frei von Eiweiss ist.

In einer Glasschale, welche in dem heissen Wasserbade stand, erhitzte ich den Reis mit möglichst wenig Wasser, bis jedes Korn vollständig weich geworden war und sich mit dem Finger zerdrücken liess. Da man hierzu nun so viel Wasser braucht, dass das Volumen des Reisbreies gross wird, musste ich sorgen, dass Gewicht und Volumen des Reisbreies nicht grösser wurden, als dies beim gefütterten Fleische der Fall war. Ein solches Volumen Reisbrei enthält aber nicht die nothwendige Menge Nährstoff, wesshalb ein ausreichender Zusatz von Fett nicht umgangen werden konnte. Den auf diese Weise hergestellten Reisbrei würde der Kater nicht angerührt haben.

Ich brachte desshalb je 600 Gramm frischen Fleischbrei in eine Glasbüchse, die einen hermetischen Verschluss ermöglichte, und erhitzte ihn im siedenden Wasserbade so lange, bis das Fleischeiweiss coagulirt und ein grosser Theil des Fleischsaftes ausgetreten war. Von diesem Fleischbrei konnte ich dann 150-200 cem Saft abgiessen, den ich benutzte, um den Reis weich zu kochen. Solchen Brei frass der Kater - aber auch nicht gern, sodass fast immer beträchtliche Mengen zurückblieben, die gewogen und in Abrug gebracht wurden. - Am willigsten frass der Kater den Brei, wenn nur Fleischbrühe, kein Schmalz zugefügt worden war.

Merkwürdig ist nun, dass dieser Brei; dem ich doch eine sehr bedeutende Menge von Fleischsaft mit seinen Salzen und Extractivstoffen zugesetzt hatte, gar keine Steigerung des Stoffwechsels bedingte. Es folgt daraus, dass es nicht die Extractivstoffe, sondern 
das Eiweiss des Fleisches ist, das die Hebung des Stoffwechsels bedingt. -

Es ist ferner bemerkenswerth, dass der gefütterte Brei kleine Mengen von Eiweiss enthielt, die dem Reis angehörten, und kleine Flöckehen und Bröckchen, die dem gekochten Fleischbrei entstammten. Man sieht daraus, dass doch eine grössere Eiweissmenge in der Nahrung zugeführt werden muss, um den Stoffwechsel auf seine normale Höhe zu erheben. Diese tritt (auf die Einheit des Körpergewichtes bezogen) aber schon dann ein, wenn das gefütterte Fleisch bei Weitem nicht ausreicht, um das Nahrungsbedürfniss zu befriedigen. Mir scheint zu folgen, dass ein höherer, gegebener Eiweissbestand der Zelle erst die Verarbeitung der grösseren Menge Fett und Kohlehydrat ermöglicht, gleichgültig, ob sie in der Nahrung zugeführt werden oder aus dem Vorrathe des Organismus zu beziehen sind.

Endlich möchte ich noeh meiner Ansicht, warum Fett und Kohlehydrate den Stoffwechsel nicht steigern, einen Ausdruck geben. Nur die Zufuhr von Eiweiss ermöglicht eine Vermehrung der Zellsubstanz, nicht aber das Fett und eben so wenig das Kohlehydrat. Im Allgemeinen ist aber die Höhe des Stoffwechsels durch die Menge der vorhandenen Zellsubstanz bedingt. Ich leugne naturlich nicht, dass eine bestimmte Menge Zellsubstanz eine grössere chemische Arbeit leistet, wenn Reize die Zellsubstanz erregen. Ob Kohlehydrate unter Umständen solche Erregung bedingen, muss die Zukunft lehren.

\section{Abschnitt V.}

Ergänzende Versuche über den Eiweissstoffwechsel des Hundes.

Da es uns besonders daranf ankommt, nachzuweisen, dass kein wesentlicher Untersehied zwischen dem Eiweissstoffwechsel des Hundes und der Katze bestehe, sodass die an diesen Thieren angestellten Untersuchungen allgemeine Geltung beanspruchen dürfen, will ich zuerst die Verdauungskraft des Hundes für Eiweiss, sowie den Einfluss der Menge des gefütterten Eiweiss auf die Höhe des Stoffwechsels in das Auge fassen.

Am leichtesten gebe ich dem Leser über alle in Betracht kommenden Werthe einen Ueberblick, wenn ich sie in der Tabelle XVII übersichtlich zusammenstellte. Zum Verständniss der 
Tabelle bemerke ich, dass ich selbst alle Analysen gemacht habe. Das Fleisch war in Büchsen als sterilisirter Brei eingemacht, und jede Büchse enthielt dasselbe Gewicht desselben Fleisches. Aller Harn und aller Koth sind in meiner Gegenwart aufgefangen. Der Hund war so abgerichtet; dass er, so oft ich es wünschte, seinen Harn in eine untergehaltene Schale entleerte, wenn er auch nur ein paar Cc. in der Blase hatte. Wasser erhielt der Hund so viel er saufen wollte. Recht störend erschien es, dass er besonders während, ja auch nach der 8 Tage dauernden Arbeitsperiode bald wenig; bald ungeheuer viel in 1 Tage soff. Bei Aufnahme von sehr viel Wasser weiss ich, dass die überschüssige Menge keineswegs in den nächsten 24 Stunden wieder ganz ausgegeben wird, sondern eine Erhöhung des Gewichtes des Thieres bedingt. - Die Arbeit, welche der Hund leisten musste, bestand darin, dass er einen schweren Wagen zog. In diesem befand sich eine von mir erfundene Vorrichtung, welche die Grösse der von dem Hunde ausgeübten Zugkraft in Gestalt einer Curve als Function des Weges auftrug, dessen Länge bekannt war. Durch Integration der Curve ist die Arbeit berechnet, die zur Körperbewegung des Thieres selbst nothwendige hinzu addirt. -

\section{(Siehe Tabelle XVII S. $480 . \downarrow$}

Die Tabelle soll lehren, dass ein Hund so viel Eiweiss verdauen kann, als seinem Bedürfniss gemäss ist und unter Umständen noch mehr.

Als das Thier vom 1. bis 9. December im Stoffwechselgleichgewicht war und mit sehr magerem Fleische ernährt wurde, sparte es noch täglich ein wenig Stickstoff; folglich hatte es alles zur Bestreitung des ganzen Stoffwechsels nöthige Eiweiss verdaut.

Vom 9. bis 17. Dec. musste der Hund täglich eine Arbeit von 109608 Kilogrammmeter ausführen und erhielt desshalb eine tägliche Zulage von 430,6 Gramm Fleisch. In der Ruhe betrug das Erhaltungsfutter 1937,5 Gramm Fleisch, während der Arbeit 2368,] Gramm. Zugeführt wurden 76,2 Gramm Stickstoff, ausgeführt 77,8 Gramm. Er hat also das grössere Eiweissquantum auch verdaut oder 22,1\% mehr, als seinem Bedürfnisse gemäss gewesen wäre.

Das Ergebniss stimmt fast ganz überein mit dem, was wir über die verdauende Kraft der Katze ermittelt haben, sodass zwischen 


\begin{tabular}{|c|c|c|c|c|}
\hline 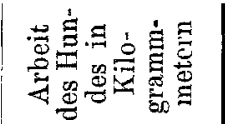 & 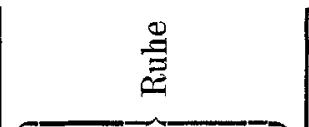 & 1 & $1 \stackrel{\stackrel{D}{E}}{E}$ & 1 \\
\hline 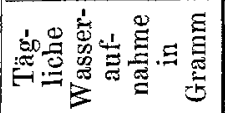 & 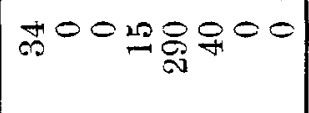 & $1 \stackrel{\circ}{\infty} \frac{\infty}{6}$ & | م. & \\
\hline 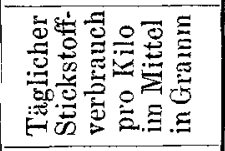 & $\stackrel{0}{\infty}$ & 1 & $\begin{array}{r}5 \\
0 \\
\end{array}$ & 1 \\
\hline 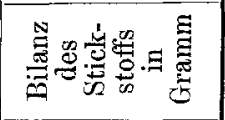 & 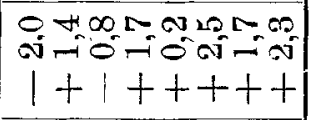 & 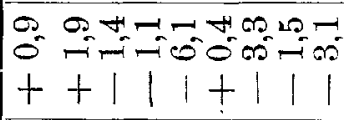 & $\begin{array}{cccc}\infty & 0 & 0 & 0 \\
0 & 2 & 0 & 0 \\
1 & 1 & 1 \\
1 & 1\end{array}$ & $\begin{array}{l}20 \\
0 \\
+ \\
\end{array}$ \\
\hline 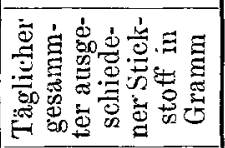 & 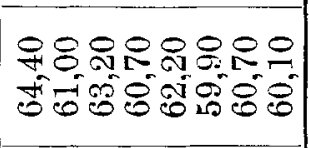 & 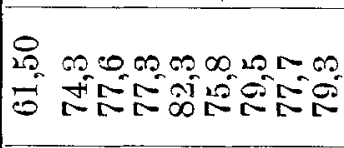 & 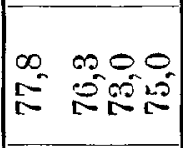 & $\infty$ \\
\hline 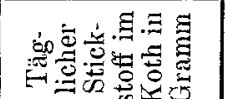 & 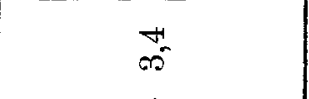 & 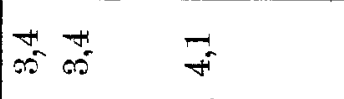 & 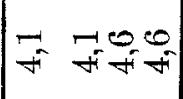 & 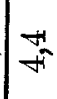 \\
\hline 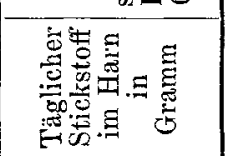 & 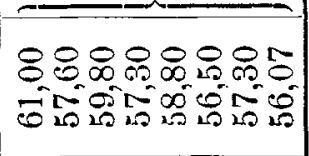 & 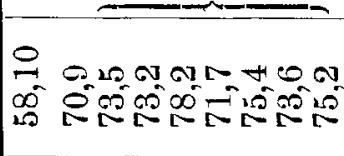 & 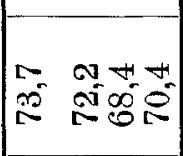 & $\dot{\sigma}^{4}$ \\
\hline 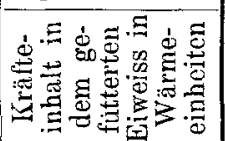 & $\begin{array}{l}\infty \\
8 \\
8 \\
0\end{array}$ & $\begin{array}{l}\infty \\
8 \\
0 \\
0\end{array}$ & 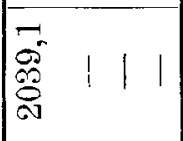 & 1 \\
\hline 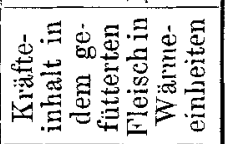 & $\stackrel{2}{2}$ & $\begin{array}{ll}\infty & 0 \\
0 & 0 \\
0 & 0 \\
0 & 0 \\
\end{array}$ & $\begin{array}{llll}\infty & \\
\infty \\
\infty \\
\infty & 1 & 1 & 1\end{array}$ & 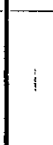 \\
\hline 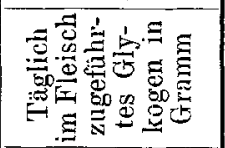 & $\stackrel{\infty}{\infty}$ & $\stackrel{\infty}{\infty}$ & {$\left[\begin{array}{cccc}\infty & 0 & 0 & 4 \\
0 & \infty & \infty & \infty\end{array}\right.$} & $\infty^{\circ}$ \\
\hline 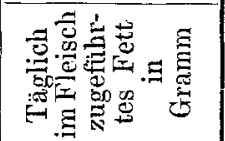 & $\infty$ & $\infty$ & $\overrightarrow{0}=\overrightarrow{0}$ & $\overbrace{0}^{\infty}$ \\
\hline 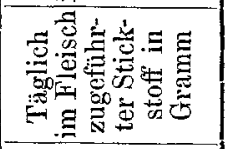 & $\vec{g}$ & î & $\left|\begin{array}{llll}\theta & 0 & 0 & 0 \\
0 & 0 & 0 & 0 \\
0 & 0 & 0 & 0\end{array}\right|$ & $\underset{⿱}{\infty}$ \\
\hline 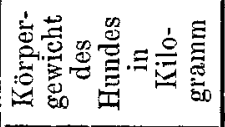 & 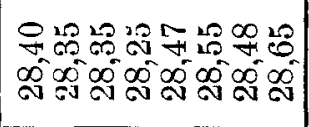 & 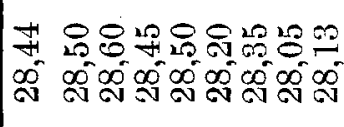 & 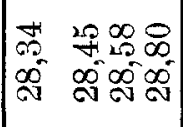 & $\overline{-\infty}$ \\
\hline 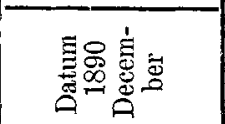 & 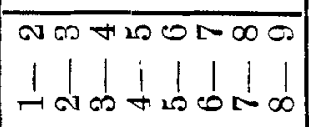 & 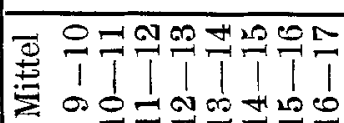 & 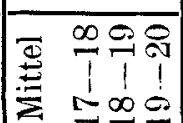 & 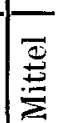 \\
\hline
\end{tabular}


beiden Thieren kein Unterschied in dieser Beziehung aufgestellt werden darf $^{1}$ ).

Nachdem hiermit die Grösse des Verdauungِsvermögens für Eiweiss festgestellt ist, gibt es keine Thatsache, welche uns berechtigt, für den Eiweissstoffwechsel wesentliche Unterschiede zwischen Hund und Katze anzunehmen.

Weil nach meinen Verbesserungen der von C. Voit und M. P ettenk ofer aufgestellten zahlreichen Bilanzen der Beweis geliefert ist, dass beim Hunde eine Umwandlung von Eiweiss in Fett nicht vorkommt, weil die vielen übrigen von C. Voit für die Fettbildung von Eiweiss beigebrachten Gründe von mir sämmtlich widerlegt sind, ist es undenkbar, dass die Katze eine Ausnahme bildet, was neuerdings Dr. Max Cremer, ein Arbeiter des Laboratoriums von Carl von Voit wieder behauptet. Ich will indessen trotzdem baldigst noch einmal genau auf diese Irrthümer zuirückkommen.

\section{Abschnitt VI.}

Zusammenfassung der Hauptergebnisse.

I. Eine Zulage von Eiweiss zu dem Erhaltungsfutter bedingt eine Vergrösserung des Stoffwechsels und der Leistungsfähigkeit des Geschöpfes.

1) Die mitgetheilte Tabel e stammt aus meiner umfangreichen noch nicht veröffentlichten Arbeit über die Quelle der Muskelkraft.

Diese Tabelle beweist, dass der Hund die ungeheuere Arbeit fast nur auf Kosten von Eiweiss allein geleistet hat.

Vergleicht man den Stickstoffverbrauch vor und während der Arbeit, so erscheint derselbe sehr und zwar um $26,5 \%$ gesteigert.

Der Vergleich nach und während der Arbeit ergibt aber nur einen Mehrverbrauch an Stickstoff von 4\%. Ganz ähnlich verhält es sich, wenn ich bei demselben Thier während der Arbeit keine Zulage gebe und wie der den Stickstoffverbrauch vor und während der Arbeit vergleiche.

Nun wird behauptet, zur Deutung des ersten Vergleichswerthes, das Thier müsse von Eiweiss allein leben, weil es kein Fett in seinem Körper besitze, während zur Deutung des zweiten Vergleichswerthes behauptet wird, das Thier zeige eine so geringe Steigerung des Stickstoffverbrauches, weil es genug Fett in seinem Körper beherberge.

Ich hoffe baldigst meine ausführliche Untersuchung über die Quelle der Muskelkraft veröffentlichen zu können. Der Grund der Verzögerung liegt darin, dass ich erst die Methoden der Fett- und Glykogenanalyse schaffen musste, und das hat nicht wenig Arbeit und Zeit beansprucht. 
II. Eine Zulage von Eiweiss zu dem Erhaltungsfutter bedingt eine Zunahme des Körpergewichtes wegen Zunahme der Zellsubstanz. Diese Vermehrung der Zellsubstanz kann unter günstigen Bedingungen bis zur Verdoppelung ihres Gewichtes und höher steigen.

III. Der Stoffwechsel und die Leistungsfähigkeit des Geschöpfes wachsen genau proportional mit der durch Eiweiss erzeugten Vermehrung des Körpergewichts. - Der höchste Stoffwechsel und die grösste Leistung'sfähigkeit können desshalb nur erzeugt werden durch die reichlichste Eiweisszufuhr in der Nahrung.

IV. Jede Verringerung der täglichen Eiweisszufuhr bedingt eine Verkleinerung des Stoffwechsels und der Leistungsfähigkeit auch dann, wenn für die entzogene Eiweissmenge Fett und Kohlehydrat von gleichem Kraftinhalt als Ersatz gegeben werden.

V. Jede Vergrösserung der Zufuhr von Fett oder Kohlehydrat in der Nahrung bedingt keine Stejgerung des Stoffwechsels, keine Erhöhung des Maschinenwerthes der Organe.

VI. Jede Zulage von Eiweiss verdrängt aus dem Stoffwechsel eine Fettmenge, die gleichen Kraftinhalt besitzt. Das setzt natürlich voraus, dass vor der Zulage der Stoffwechsel nicht bloss durch Eiweiss, sondern auch durch Fett u. s. w. unterhalten würde.

VII. Die Gesetze des Eiweissstoffwechsels sind dieselben bei Hund und Katze.

VIII. Eine im thierischen Körper sich vollziehende Entstehung von Fett aus Eiweiss, welche von Carl von Voit und Max Cremer behauptet wird, gibt es nicht.

IX. Der Mensch kann sein ganzes Nahrungsbedürfniss nicht mit Eiweiss allein befriedigen, weil er nicht so viel Eiweiss zu verdauen vermag. Nach den von mir und meinen Schülern ausgeführten Bestimmungen decken nach ihrem Instinkte lebende junge Männer ungefähr $1 / 5$ des Bedürfnisses mit Eiweiss. Da der Mensch aber viel mehr Eiweiss verdauen kann, muss man, weil der Instinkt sich gegen ausschliessliche Fleischkost sträubt, die allerdings nicht erwiesene Möglichkeit in Betracht ziehen, dals der Nutzen, den die vermehrte Eiweisszufuhr bedingt, bei den Omnivoren eine obere Grenze habe. 